\title{
Experimental Investigation of the Effects of the Gangue Particle Size on the Evolution Rules of Key Seepage Parameters
}

\author{
Lihua Wang $\mathbb{D}^{1}{ }^{1}$ Jixiong Zhang $\mathbb{D}^{1,2}$ Yongqi Wei, ${ }^{3}$ Cunli Zhu $\mathbb{D}^{1,2}$ and Gaolei Zhu $\mathbb{D}^{1,2}$ \\ ${ }^{1}$ School of Mines, China University of Mining and Technology, Xuzhou, 221116 Jiangsu, China \\ ${ }^{2}$ State Key Laboratory of Coal Resources and Safe Mining, Xuzhou, 221116 Jiangsu, China \\ ${ }^{3}$ Yanzhou Coal Mining Co. Ltd., Jining 272100, China \\ Correspondence should be addressed to Cunli Zhu; cumtzhucunli@163.com
}

Received 15 July 2021; Revised 2 September 2021; Accepted 8 November 2021; Published 26 November 2021

Academic Editor: Afshin Davarpanah

Copyright (c) 2021 Lihua Wang et al. This is an open access article distributed under the Creative Commons Attribution License, which permits unrestricted use, distribution, and reproduction in any medium, provided the original work is properly cited.

In order to deal with solid wastes and protect the fragile ecological environment on the ground, using gangues as the filling materials in the underground goaf can not only achieve favorable waste disposal but also alleviate surface subsidence and protect surface buildings and the ecological environment, with great practical significance and application prospects. During the water seepage process, the evolution rules of inner seepage channels in the bulk filling materials are the theoretical foundation for the realization of water-preserved mining. In order to gain clear knowledge of the seepage characteristics of the bulk filling gangues with different sizes, the evolution rules of some seepage parameters mainly including the displacement, the porosity, and the permeability of gangues and hydraulic pressure were analyzed via COMSOL numerical simulation. The evolution rules of the seepage characteristics of the bulk filling materials with different sizes were revealed by combining the present experimental and numerical results. Moreover, the present seepage experiment was proved to be reliable by comparing with numerical simulation results. This work can provide theoretical foundation for investigating the evolution characteristics of inner seepage paths in the bulk filling materials and selecting appropriate bulk filling materials under different stress and seepage environments.

\section{Introduction}

Coal mining has imposed serious effect on the balance of the underground water and surface water system in China [1-4]. During coal mining especially the modern mining process, original overlying strata are severely damaged under intense mining in the underground working face, thereby forming a lot of water-diversion fractures [5-8]. When the water-diversion fractures are connected with the aquifer, underground water can flow to the working face along the water-diversion channels formed by fractures, which can pose serious threat to safety production in mines, accompanied with the decline in the underground water level and the pollution of water quality [9-12]. According to the statistics, approximately $2.54 \mathrm{~m}^{3}$ underground water is polluted for the mining of 1 ton of coal [13-15]. Therefore, how to achieve adequate protection of water resources in coal mining is the problem demanding prompt solution in the coal mining industry.
Mining with filling or backfill mining is an effective measure for inhibiting the development height of the mining-induced water-diversion fractured zone and protecting the aquifer. Gaining in-depth knowledge of the seepage rules of bulk filling materials with different particle sizes in a complex underground water environment can lay solid theoretical foundation for achieving water-preserved mining [16-19]. Currently, scholars from all over the world have conducted a great deal of research on the seepage rules of bulk filling materials. By combining laboratory test, theoretical analysis, and field application, $\mathrm{Ma}$ et al. examined nonDarcy hydraulic characteristics and deformation behaviors of bulk gangues and concluded that both porosity and permeability of gangues increased with the increase of the original GSG and the decrease of the stress rate [20]. Raziperchikolaee et al. focused on the relation between permeability of the deformed rock joints and seismic source response, established the fluid flow-geomechanics-seismicity 
model at microscale, and investigated the displace response and failure mechanisms of microfractures in the sandstone samples that were developed along the joint during the development [21]. Li et al. investigated the effects of the particle size on compressive deformation and particle damage of the filling gangues in the goaf and analyzed the compressive deformation, particle clustering distribution, and gauge bulk shape change rules of the filling gangues [22]. Minh et al. explored the effects of the elasticity of pores on the solute transport process in viscous unstable aquifers and constructed a coupled flow, migration, and geomechanics framework for simulating the diffusion, mixing, and deformation mechanisms of stress-sensitive aquifers in the fingering process [23]. Zhang et al. investigated pore pressure evolution rules and energy loss characteristics during the seepage process of different sizes of gangues and performed tests on the permeability, mass loss, and pore pressure of gangues in the seepage process [24]; according to their test results, the mass loss of fractured gangues increased with the disproportionate increase of the large particle size. Conclusively, despite of substantial laboratory tests on the permeability of bulk filling materials, scholars [25-28] mainly focused on basic seepage parameters and fundamental physical/mechanical characteristics of bulk filling materials while neglecting the effects of the particle sizes of bulk filling materials on the seepage characteristics and the inner seepage evolution rules.

In this work, the goaf was filled with different sizes of solid wastes as the bulk filling materials. Under the complex stope environment, water in upper and lower adjacent artesian aquifers seeps constantly into the goaf through the water-diversion fractured zone and different geologic structures; accordingly, bulk filling materials are always in infiltrative mines. The compact filling body changes under coupled crustal stress and underground water flow. The bulk materials are constantly compacted when being subjected to the crustal stress, and the particles are gradually crushed and refined, accompanied with constant changes of pores among particles and the fluid's seepage channels. Next, as the size particle of bulk filling materials changes, the confined water enters into the filling body in the goaf via the waterdiversion fractured zone; as the seepage pressure increases, pore channels in the filling body change gradually and the bulk filling materials with different sizes vary in seepage channels and rules. Investigating the seepage characteristics of bulk filling materials with different sizes is the key scientific problem in water-preserved mining.

In this study, based on laboratory test and numerical simulation, the effects of the filling gangues with different particle size ranges $(0 \sim 5 \mathrm{~mm}, 5 \sim 10 \mathrm{~mm}, 10 \sim 15 \mathrm{~mm}$ and $15 \sim 20 \mathrm{~mm})$ on seepage discharge and permeability parameters were investigated in depth. The evolution rules of displacement, porosity, permeability of gangues and hydraulic pressure after the filling were simulated using COMSOL numerical simulation software. Finally, the evolution rules of various seepage parameters after the filing of different sizes of materials were revealed by above laboratory and simulation data. Meanwhile, the reliability of the experimental results was validated by the present numerical simulation data. This work can provide theoretical foundation for examining the evolution characteristics of inner seepage paths of the bulk filling materials and selecting appropriate bulk filling materials under different stress and seepage environments.

\section{Materials and Methods}

The filling materials mainly consisting of different sizes of gangues are essentially a kind of discontinuous media [29-32], which themselves change in the compaction process.

2.1. Experimental Materials. The bulk filling materials in this work are mainly composed of different sizes of gangues. The gangues were directly collected from mines and the specimens with different size ranges were prepared, as shown in Figure 1.

Before the experiment, large gangues were collected and crushed. To be specific, large gangues were artificially crushed to the fragments with a size range of $200 \sim 300 \mathrm{~mm}$ so that the gangue fragments can smoothly pass through the inlet of the crusher; next, small gangues passed through the square hole sieves for step-by-step screening so as to obtain small gangues with different size ranges $(0 \sim 5 \mathrm{~mm}$, $5 \sim 10 \mathrm{~mm}, 10 \sim 15 \mathrm{~mm}$, and $15 \sim 20 \mathrm{~mm}$ ). Figure 1 shows the gangues with different sizes after crushing.

\subsection{Experimental Method and Devices}

2.2.1. Axial Loading. As shown in Figure 2, the experimental loading system was used to offer the axial force for material compaction. Using the WAW-1000D Electro-Hydraulic Servo Universal Tester, the loading was applied in a displacement mode at a rate of $0.5 \mathrm{~mm} / \mathrm{min}$. The tester can display the measurement process and experiment results in real time. The tester with a maximum experimental force of $1000 \mathrm{kN}$ can automatically measure the material's feature points and plot stress/strain and stress/displacement curves. When investigating the seepage characteristics of different sizes of gangues under axial compressive stress, the axial loading force was set as $4 \mathrm{MPa}, 6 \mathrm{MPa}, 8 \mathrm{MPa}, 10 \mathrm{MPa}, 16 \mathrm{MPa}$, and $20 \mathrm{MPa}$.

2.2.2. Seepage System. The seepage characteristics of different sizes of gangues were investigated at a hydraulic pressure of $2 \mathrm{MPa}, 3 \mathrm{MPa}, 4 \mathrm{MPa}, 5 \mathrm{MPa}, 6 \mathrm{MPa}, 7 \mathrm{MPa}$, and $8 \mathrm{MPa}$. In order to achieve water permeation in bulk filling materials, constant hydraulic pressure was steadily applied on the bottom of the materials under the stress, thereby generating pressure difference between the upper atmospheric pressure. Accordingly, water can freely flow in from one end of the bulk filling materials and out from the upper end. The pressure at the inlet of the bulk filling materials was controlled by the hydraulic power unit so as to provide different inlet pressures for the bulk filling materials.

Figure 3 shows the experimental seepage system, which mainly consists of the permeameter, the hydraulic-pressure control system, and the data acquisition instrument. In the present study, the permeameter was horizontally placed on the loading platform, whose bottom was in contact with the loading platform. The cylinder tube was placed on the bottom and sealed by O-shaped rubber seal rings. The porous plates were placed on the bottom of the cylinder 


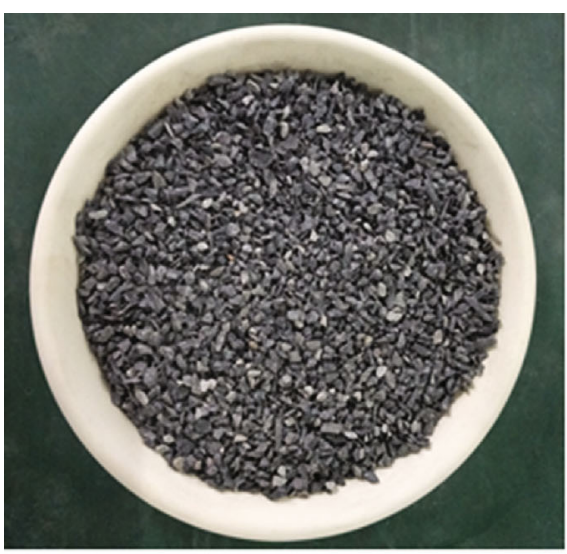

0 5 $\mathrm{mm}$

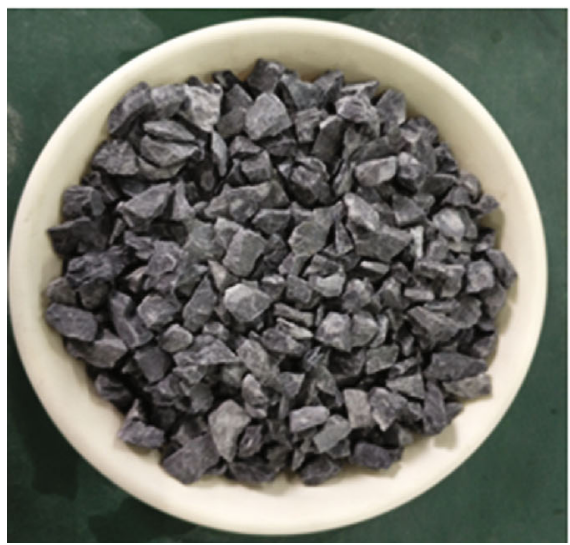

$10 \sim 15 \mathrm{~mm}$

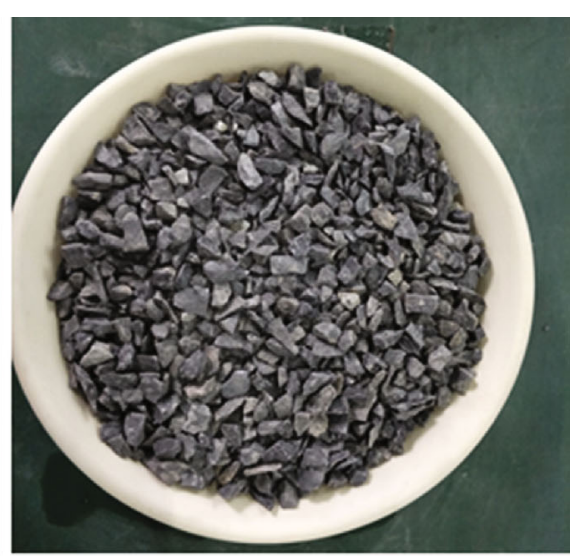

5 10 $\mathrm{mm}$

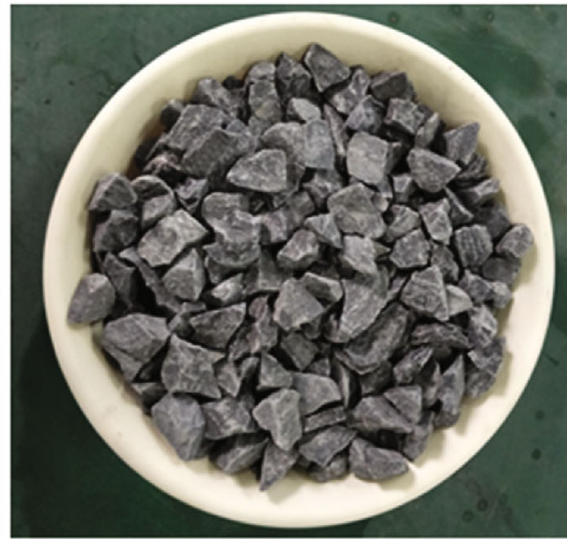

15 20 mm

Figure 1: Pictures of the gangues with different sizes.

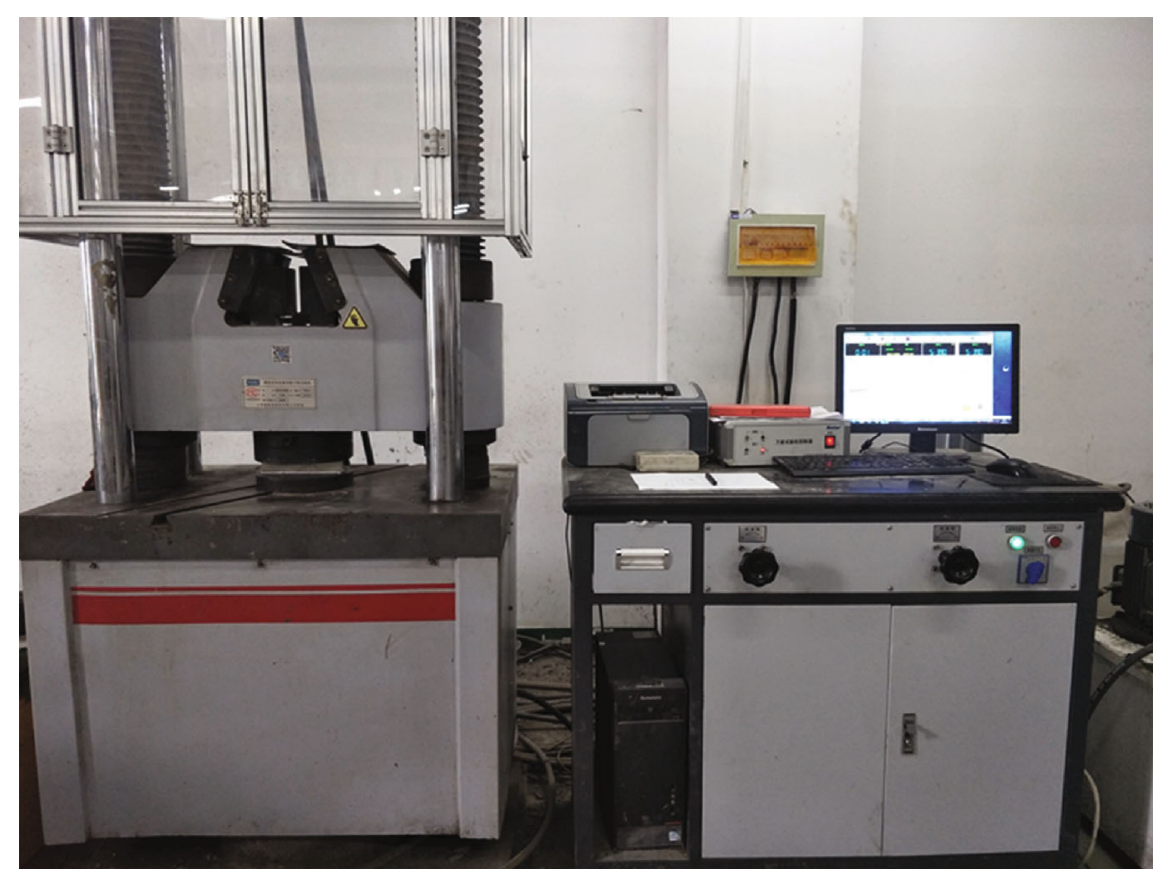

FIGURE 2: Picture of the experimental loading system. 


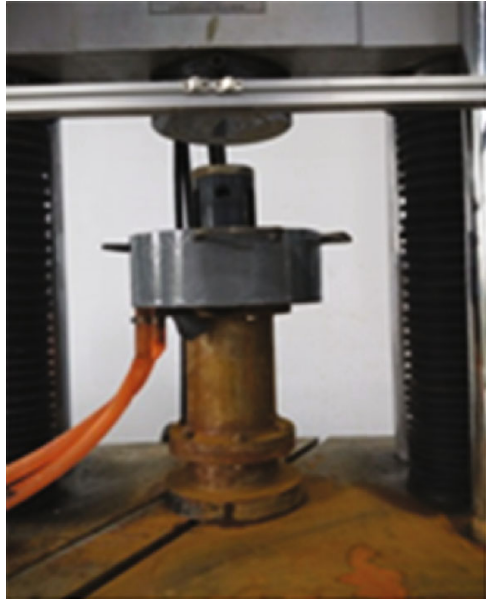

(a) Permeameter

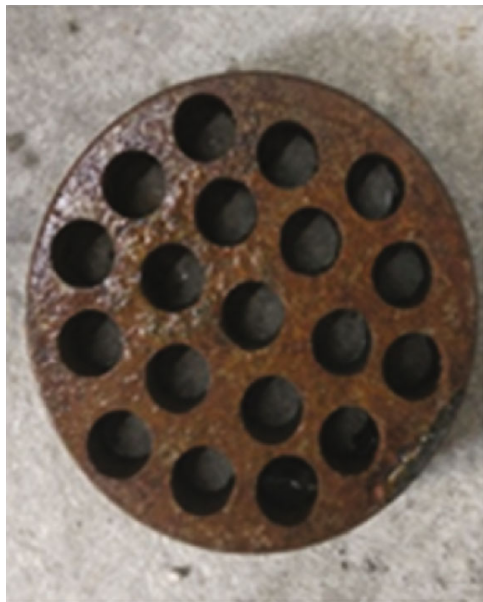

(d) Piston

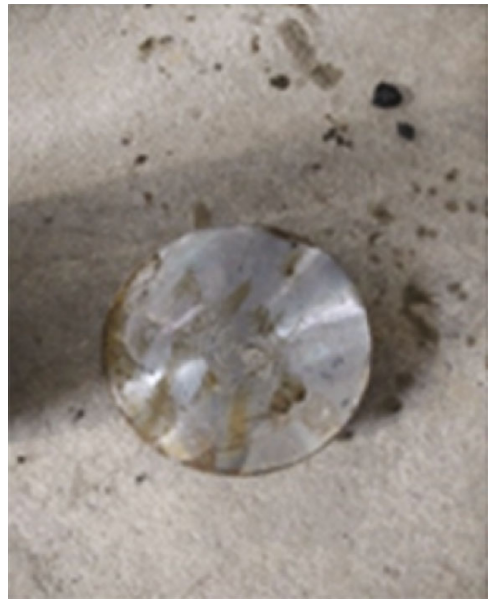

(g) Balance structure

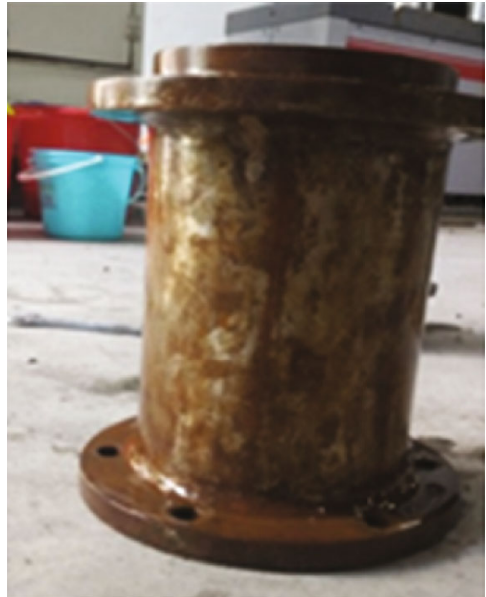

(b) Cylinder tube

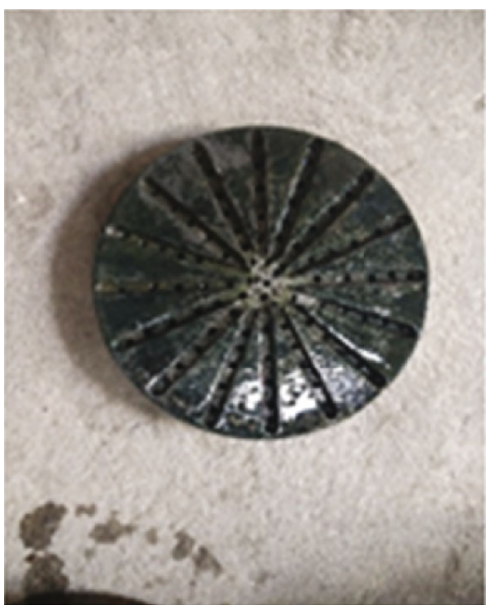

(e) Porous plate

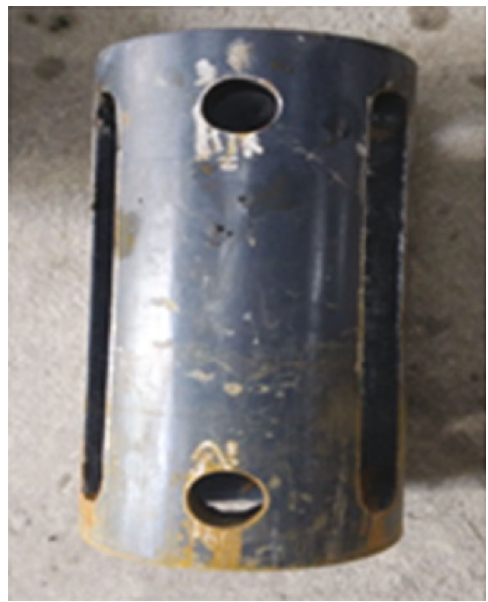

(h) Bearing column

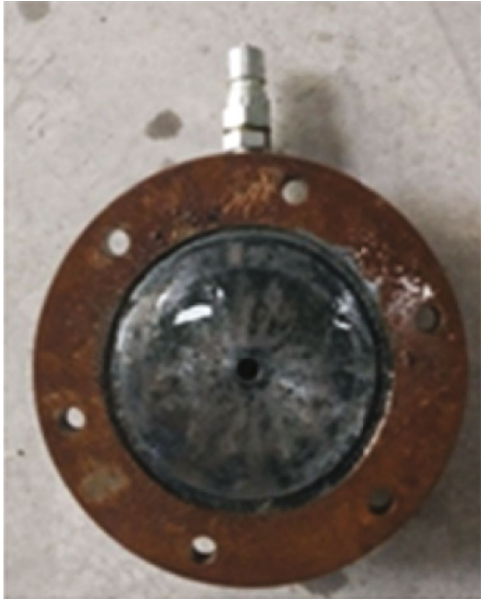

(c) Bottom support

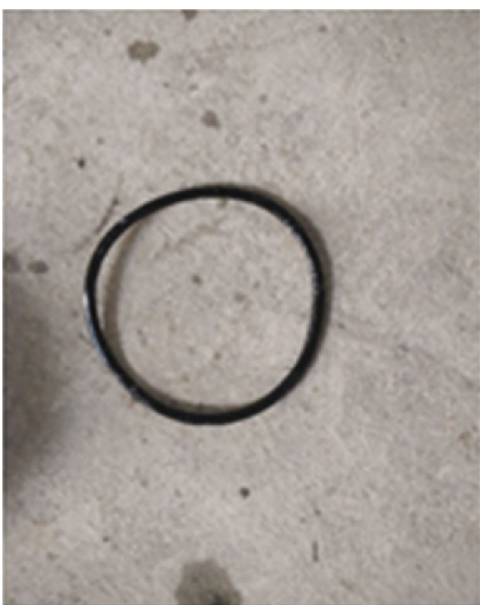

(f) Sealing ring

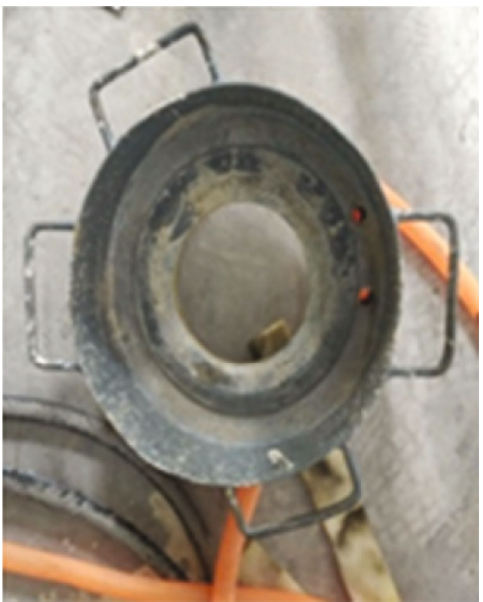

(i) Overflow barrel

FIGURE 3: Picture of the experimental seepage system.

tube. The cylinder tube was filled with bulk filling specimen with the piston on the surface. The piston was connected with the bearing column, the balance structure, and the overflow barrel. Finally, vertical axial stress can be applied on the bulk filling materials by the load of the tester via the overflow barrel cover, the overflow barrel, and the piston.
2.3. Measuring Principle of the Seepage Test. The present experimental system was used for measuring seepage characteristics of bulk filling materials with the steady method. In order to simulate the effects of the crustal stresses at different burial depths on the seepage characteristics of bulk filling materials, the seepage behaviors under different axial 


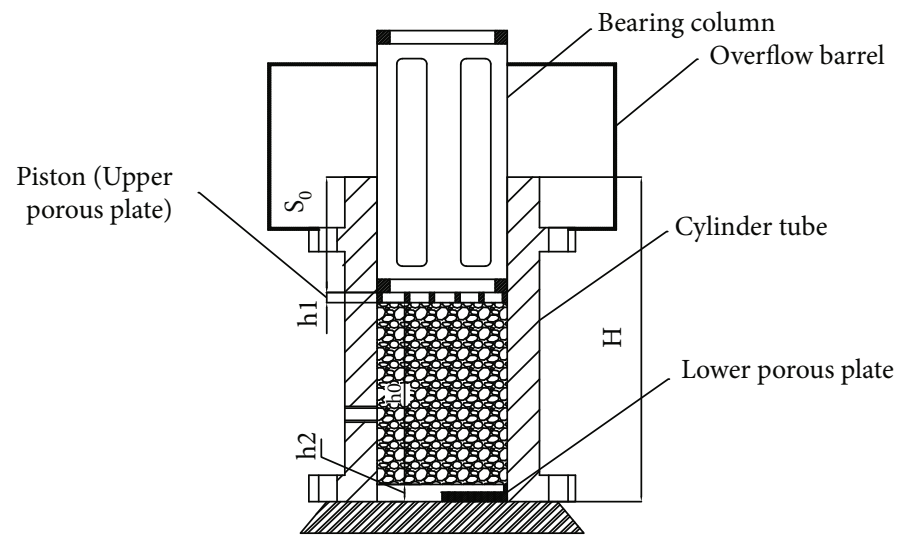

FIGURE 4: Illustration of the loading process of the permeameter.

TABLE 1: Test scheme.

\begin{tabular}{lccr}
\hline Test order & Particle size of gangues $(\mathrm{mm})$ & Axial load $(\mathrm{MPa})$ & Hydraulic pressure $(\mathrm{MPa})$ \\
\hline i-1 & $0 \sim 5$ & $4,6,8,10,16,20$ & $2,3,4,5,6,7,8$ \\
i-2 & $5 \sim 10$ & $4,6,8,10,16,20$ & $2,3,4,5,6,7,8$ \\
i-3 & $10 \sim 15$ & $4,6,8,10,16,20$ & $2,3,4,5,6,7,8$ \\
i-4 & $15 \sim 20$ & $4,6,8,10,16,20$ & $2,3,4,5,6,7,8$ \\
\hline
\end{tabular}

stresses were tested with the axial stress control method. According to the mining engineering environment, the axial stress in preliminary design was set in the range of $4 \sim 20 \mathrm{MPa}$. The axial stress was uniformly increased and the displacement under each axial stress $\left(S_{0}\right)$ was recorded. Meanwhile, the residual height can be calculated by the initial filling height and the thicknesses of the upper and the lower porous plates, i.e., $h=H-S_{0}-h_{1}-h_{2}$, as the principle shown in Figure 4.

The hydraulic pressure at 4 levels or above was injected from the bottom of the bulk materials via the hydraulic pump. Based on practical engineering background and the current test condition, the hydraulic pressure was preliminarily designed within $1 \sim 7 \mathrm{MPa}$. Next, the value when the flow reached stability at each level of hydraulic pressure was read, i.e., the velocity at the steady state, denoted as $v$, can be obtained. The corresponding pressure gradient $G_{P}$ corresponding to each level of hydraulic pressure equals to the ratio of the difference between the pressure at the outlet and the hydraulic pressure at the inlet to the height of the bulk materials, i.e., $G_{P}=-P / h$. Next, the scatter diagrams can be plotted given each level of pressure gradient and the corresponding steady-state seepage velocity and the permeability $k$ and non-Darcy factor $\beta$ at the axial pressure can be obtained via fitting formula (1) as follows:

$$
G_{P}=-\frac{\mu}{k}-\rho \beta v^{2}
$$

\section{Experimental Schemes and Proportions}

3.1. Proportion Settings. In order to explore the seepage characteristics of different sizes of gangue filling materials under different axial loads and confining pressures, the gangue par- ticle size range was set as $0 \sim 5 \mathrm{~mm}, 5 \sim 10 \mathrm{~mm}, 10 \sim 15 \mathrm{~mm}$, and $15 \sim 20 \mathrm{~mm}$ and the axial load was set as $4 \mathrm{MPa}, 6 \mathrm{MPa}$, $8 \mathrm{MPa}, 10 \mathrm{MPa}, 16 \mathrm{MPa}$, and $20 \mathrm{MPa}$, while the hydraulic pressure was set as $2 \mathrm{MPa}, 3 \mathrm{MPa}, 4 \mathrm{MPa}, 5 \mathrm{MPa}, 6 \mathrm{MPa}$, $7 \mathrm{MPa}$, and $8 \mathrm{MPa}$, respectively; the test scheme is shown in Table 1.

The axial load was set at $4 \sim 20 \mathrm{MPa}$ so as to simulate the crustal stress from a shallow-buried coal seam to a deep well at a depth of several kilometers. Table 2 shows the axial load and corresponding oil pressure via calculation. The hydraulic pressure was set within a range of $2 \mathrm{MPa}$ to $8 \mathrm{MPa}$, which can almost satisfy the pressure range of underground confined water. The axial load was cyclically applied, i.e., the axial load at the next level was applied for seepage after the load of each level of axial load. If no water passed at a hydraulic pressure of $7 \mathrm{MPa}$ (i.e., water flow at a steady state equaled to 0 ), the loading stopped. It should be noted that steady state refers to flow reaching a stable value within a short time.

3.2. Testing Process. The screened gangues with different sizes were soaked in water for 24 hours. Next, the gangues within same particle size range after soaking were put into the permeameter. The axial loads at $4 \mathrm{MPa}, 6 \mathrm{MPa}, 8 \mathrm{MPa}$, $10 \mathrm{MPa}, 16 \mathrm{MPa}$, and $20 \mathrm{MPa}$ were loaded on the WAW1000D Electro-Hydraulic Servo Universal Tester. Under each level of axial load, the hydraulic pressure was increased step by step and the flow readings under different hydraulic pressures were read. Figure 5 illustrates the detailed testing process.

\section{Experimental Results}

\subsection{Measured Results of Physical Characteristics}


TABLE 2: Conversion between axial stress and oil pressure.

\begin{tabular}{lcccccccc}
\hline$P(\mathrm{MPa})$ & 1.5 & 2 & 4 & 6 & 8 & 10 & 16 & 20 \\
$S\left(\mathrm{~m}^{2}\right)$ & 0.00785 & 0.00785 & 0.00785 & 0.00785 & 0.00785 & 0.00785 & 0.00785 & 0.00785 \\
$F(\mathrm{~N})$ & 11775 & 15700 & 31400 & 47100 & 62800 & 78500 & 125600 & 157000 \\
Oil pressure $(\mathrm{KN})$ & 11.775 & 15.7 & 31.4 & 47.1 & 62.8 & 78.5 & 125.6 & 157 \\
\hline
\end{tabular}

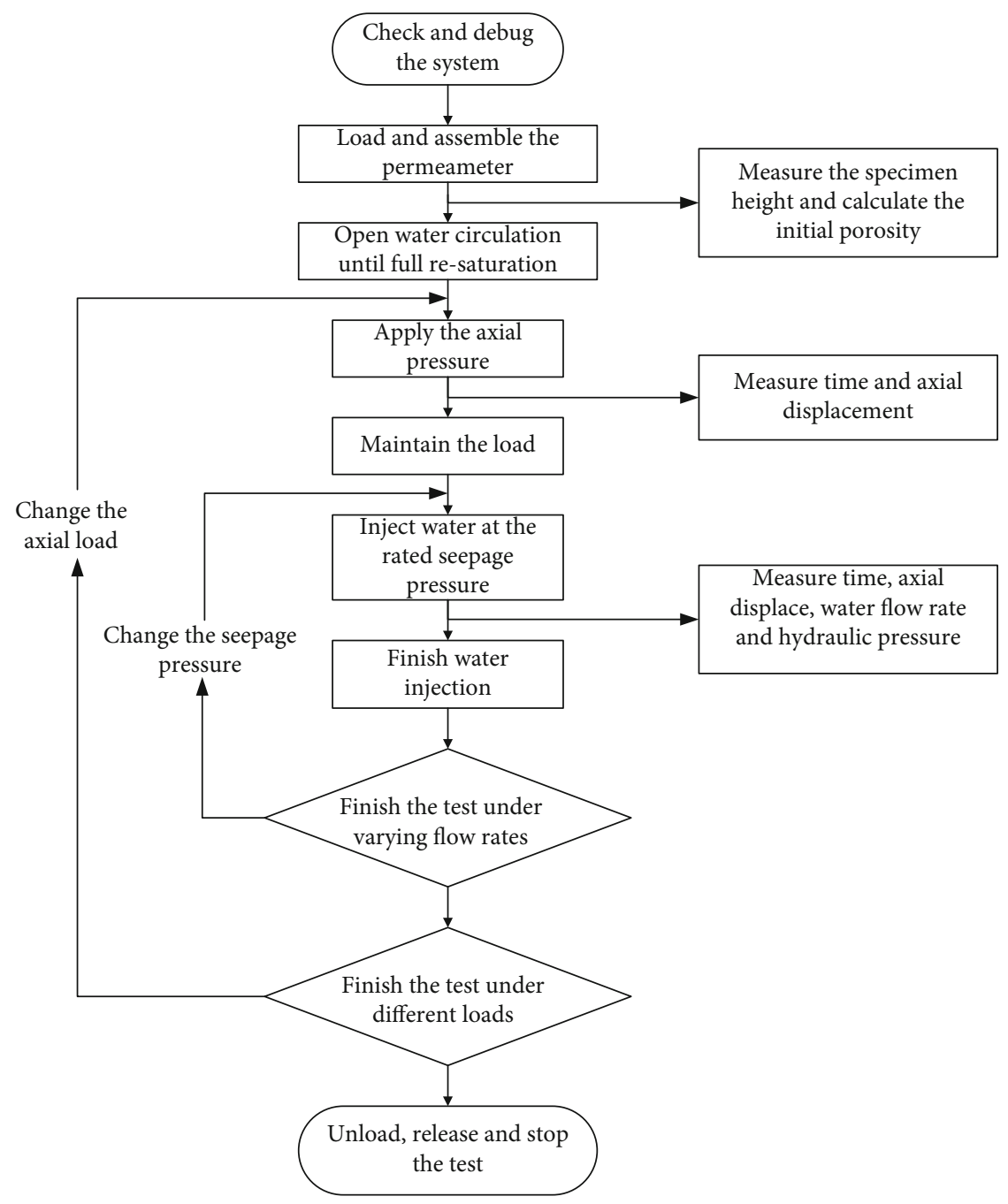

FIGURE 5: Illustration of the present testing process.

Table 3: Densities of the gangue specimens with different sizes.

\begin{tabular}{lccccc}
\hline Materials & Natural density & Saturated density & & \multicolumn{2}{c}{ Accumulation density $\left(\mathrm{g} / \mathrm{cm}^{3}\right)$} \\
\hline \multirow{2}{*}{ Gangue specimen } & \multirow{2}{*}{2.08} & 2.12 & $0 \sim 5$ & $5 \sim 10$ & $10 \sim 15$ \\
& & & 1.475 & 1.409 & 1.398 \\
\hline
\end{tabular}

TABLE 4: Initial porosities of different sizes of gangues.

\begin{tabular}{lcccc}
\hline Material & $0 \sim 5 \mathrm{~mm}$ & $5 \sim 10 \mathrm{~mm}$ & $10 \sim 15 \mathrm{~mm}$ & $15 \sim 20 \mathrm{~mm}$ \\
Gangue & 0.34 & 0.42 & 0.43 & 0.47 \\
\hline
\end{tabular}


TABLE 5: Seepage discharges of different sizes of gangues.

\begin{tabular}{|c|c|c|c|c|c|c|c|c|c|}
\hline \multirow{2}{*}{ Particle size (mm) } & \multirow{2}{*}{ Axial load (MPa) } & \multicolumn{8}{|c|}{ Hydraulic pressure (MPa) } \\
\hline & & $0 \sim 2$ & 2 & 3 & 4 & 5 & 6 & 7 & 8 \\
\hline \multirow{4}{*}{$0 \sim 5$} & 4 & 6.741 & 7.638 & 9.261 & 12.316 & 14.427 & - & - & - \\
\hline & 6 & 3.59 & 5.78 & 6.93 & 7.57 & 8.505 & - & - & - \\
\hline & 8 & 0 & 0 & 0 & 0 & 0.504 & 3.39 & 5.04 & 6.21 \\
\hline & 10 & 0 & 0 & 0 & 0 & 0 & 0 & 0 & 0 \\
\hline \multirow{5}{*}{$5 \sim 10$} & 4 & 62.43 & - & - & - & - & - & - & - \\
\hline & 6 & - & 5.67 & 8.379 & 11.214 & 12.97 & 14.679 & - & - \\
\hline & 8 & - & 6.237 & 7.632 & 8.26 & 8.31 & - & - & - \\
\hline & 10 & - & 0 & 0 & 0 & 0.315 & 1.157 & 1.796 & 4.898 \\
\hline & 16 & 0 & 0 & 0 & 0 & 0 & 0 & 0 & 0 \\
\hline \multirow{4}{*}{$10 \sim 15$} & 4 & 62.43 & - & - & - & - & - & - & - \\
\hline & 6 & - & 7.501 & 16.52 & 26.42 & 34.43 & - & - & - \\
\hline & 8 & - & 6.237 & 7.632 & 8.26 & 8.31 & - & - & - \\
\hline & 10 & 0 & 0 & 0 & 0 & 0 & 0 & 0 & 0 \\
\hline \multirow{5}{*}{$15 \sim 20$} & 4 & 62.43 & - & - & - & - & - & - & - \\
\hline & 6 & 13.549 & 62.43 & - & - & - & - & - & - \\
\hline & 8 & 6.77 & 7.371 & 7.632 & 12.66 & 20.16 & 24.61 & - & - \\
\hline & 10 & 0 & 2.16 & 3.41 & 3.59 & 5.66 & - & - & - \\
\hline & 16 & 0 & 0 & 0 & 0 & 0 & 0 & 0 & 0 \\
\hline
\end{tabular}

Because of limited range of the flowmeter, the flow rate of large-size gangues exceeded the measuring range, and simultaneously, small-size gangues were tightly compacted under large axial load, whose flow rates were fixed at 0 at different hydraulic pressures. Therefore, the permeability at that axial load condition can not be monitored.

4.1.1. Measurement of Gangue Density. This study selected a natural gangue, some bulk filling materials under a natural state, or saturated bulk filling materials after 24-hour soaking for measurement. The mass and the volume were weighed by the electronic balance and appropriate measuring glass so as to calculate the density. It should be noted that the experimenters should look at the front of the measuring glass as horizontally as possible so as to obtain accurate readings. Finally, the calculated results were averaged as the mean density of the bulk filling material. The specific calculation formula is shown in formula (2) as follows:

$$
\rho_{s}=\frac{1}{k} \sum_{i=1}^{n} \rho_{i}=\frac{1}{k} \sum_{i=1}^{n} \frac{m_{i}}{V_{i}}
$$

where $\rho_{s}$ denotes the specimen density, $k$ denotes the selected number of measurements, $\rho_{i}$ denotes the specimen density in the $i$ th measurement, $m_{i}$ denotes the specimen mass in the $i$ th measurement, and $V_{i}$ denotes the specimen volume in the $i$ th measurement.

As described above, the filling gangues are a kind of discontinuous media. The accumulation density is a quite important parameter for determining the consumption of the filling materials in the goaf. A certain mass of gangue blocks within a same particle size range was randomly selected and placed into the circular cylinder tube. The volume of the crushed gangue blocks can thus be determined by measuring the loading height and the cylinder tube size. In combination with the total mass of the gang- ues, the packing density calculation formula is shown in formula (3) as follows:

$$
\rho_{b}=\frac{m_{b}}{V_{b}}=\frac{4 m_{b}}{\pi d^{2} h_{b}}
$$

where " $\rho_{b}$ " denotes the accumulation density of the gangue specimen, " $m_{b}$ " denotes the total mass of the gangue specimen in the tube, " $V_{b}$ " denotes the volume of the gangue specimen in the tube, " $d$ " denotes the inner diameter of the tube, and " $h_{b}$ " denotes the height of the gangue specimen in the tube.

According to above measurement methods and computational formulas, natural densities, saturated densities, and accumulation densities of the filing gangues with different sizes were calculated, as the results shown in Table 3.

4.1.2. Initial Porosity of the Gangue Specimen. Porosity refers to the ratio of the pore volume between blocks to the accumulation volume when the crushed gangues were packed, which can directly reflect the compaction degree of the filling gangues. A higher porosity is indicative of a lower compaction degree, which is conductive for the water flow; contrarily, water can more hardly pass through the specimen with lower porosity. The porosity calculation formula is shown in formula (4) as follows:

$$
\phi_{o}=\frac{V_{b}-V_{e}}{V_{b}}=1-\frac{V_{e}}{V_{b}}=1-\frac{4 m_{b}}{\pi d^{2} h_{b} \rho_{s}},
$$




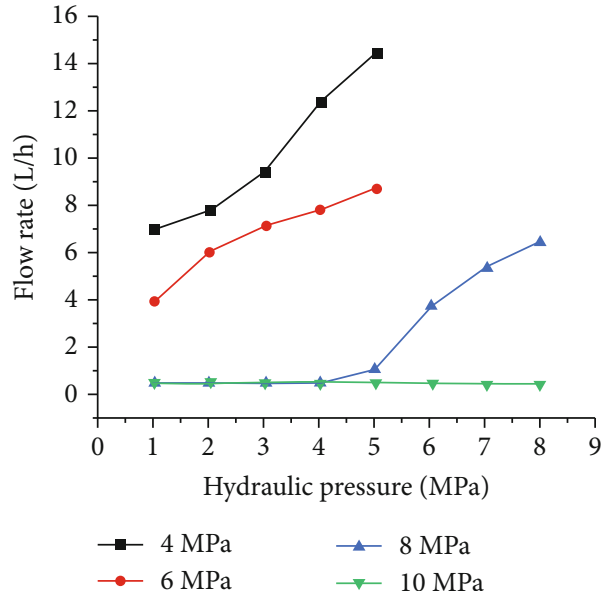

(a) $0 \sim 5 \mathrm{~mm}$

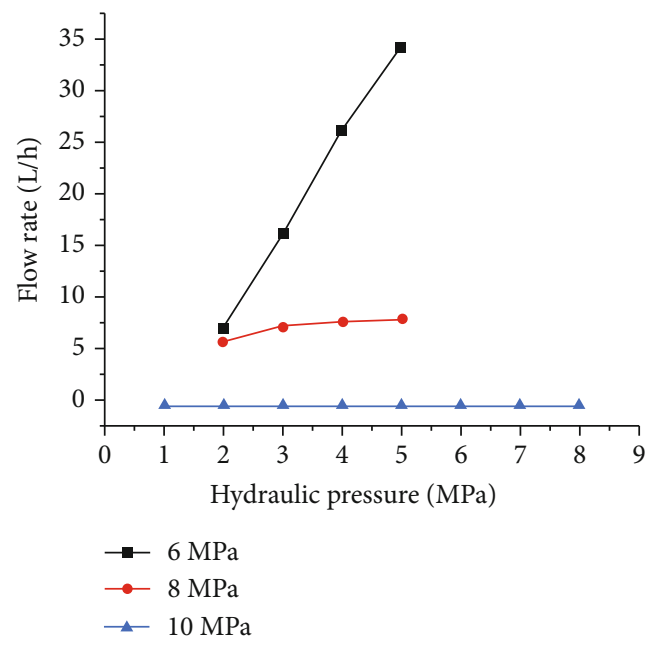

(c) $10 \sim 15 \mathrm{~mm}$

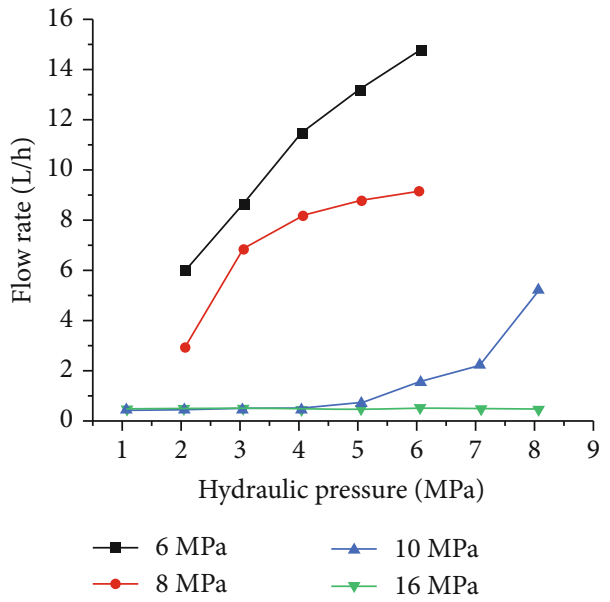

(b) $5 \sim 10 \mathrm{~mm}$

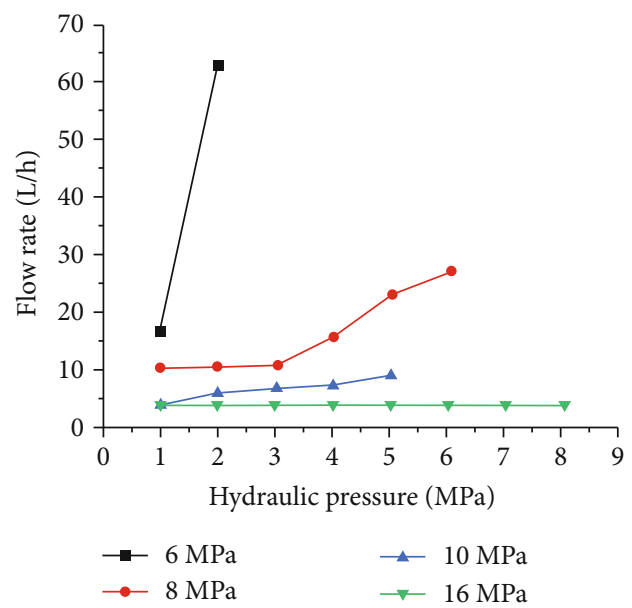

(d) $15 \sim 20 \mathrm{~mm}$

FIGURE 6: Relations between the flow rate and hydraulic pressure for the filling gangues with different size ranges.

where $\phi_{o}$ denotes the original porosity of the gangue specimen and denotes the protolith volume. Table 4 lists the measured porosities of different sizes of filling gangues.

4.2. Effect of the Particle Size on the Flow Rate and Permeability Parameters. In order to clarify the effects of the particle size on the flow rate and permeability parameters, the gangues with different size ranges $(0 \sim 5 \mathrm{~mm}$, $5 \sim 10 \mathrm{~mm}, 10 \sim 15 \mathrm{~mm}$, and $15 \sim 20 \mathrm{~mm}$ ) were selected for seepage experiments under an axial load of $4 \mathrm{MPa}, 6 \mathrm{MPa}$, $8 \mathrm{MPa}, 10 \mathrm{MPa}$, and $16 \mathrm{MPa}$, respectively. Table 5 lists the seepage discharges of different sizes of gangues at a same axial load but different hydraulic pressures.

As listed in Table 5, when the seepage discharge equaled to 0 , the loading on the bulk filling materials stopped. At a fixed axial load, the seepage discharges of different sizes of gangues increased gradually with the increasing hydraulic pressure. This can be attributed to the discontinuity of bulk filling materials. As the hydraulic pressure increased, more water-diversion fractures appeared in the filling materials, accompanied with a larger number of water-diversion fracture zones throughout the filling materials. Figure 6 shows the variations of seepage discharge and hydraulic pressure with the axial load for different sizes of gangues.

It can be observed in Figure 6 that seepage discharge dropped with the axial load at a decreasing rate. Meanwhile, the flow rate at a fixed axial load showed no change and approached to 0 . This is mainly due to the fact that the bulk filling materials were gradually compacted under increasing axial load, accompanied with gradual compaction of water-diversion channels in the filling materials. When the axial load increased to a certain value, the pores in the bulk filling materials were gradually compacted and water cannot be infiltrated into the filling materials; at that moment, the seepage discharge of the bulk filling materials equaled to 0 . When the particle size of bulk filling materials increased steadily, the seepage discharge of water increased with the increasing hydraulic pressure at a fixed axial load. On account of a low bonding degree, water channels were generally large in large-size gangues. In 


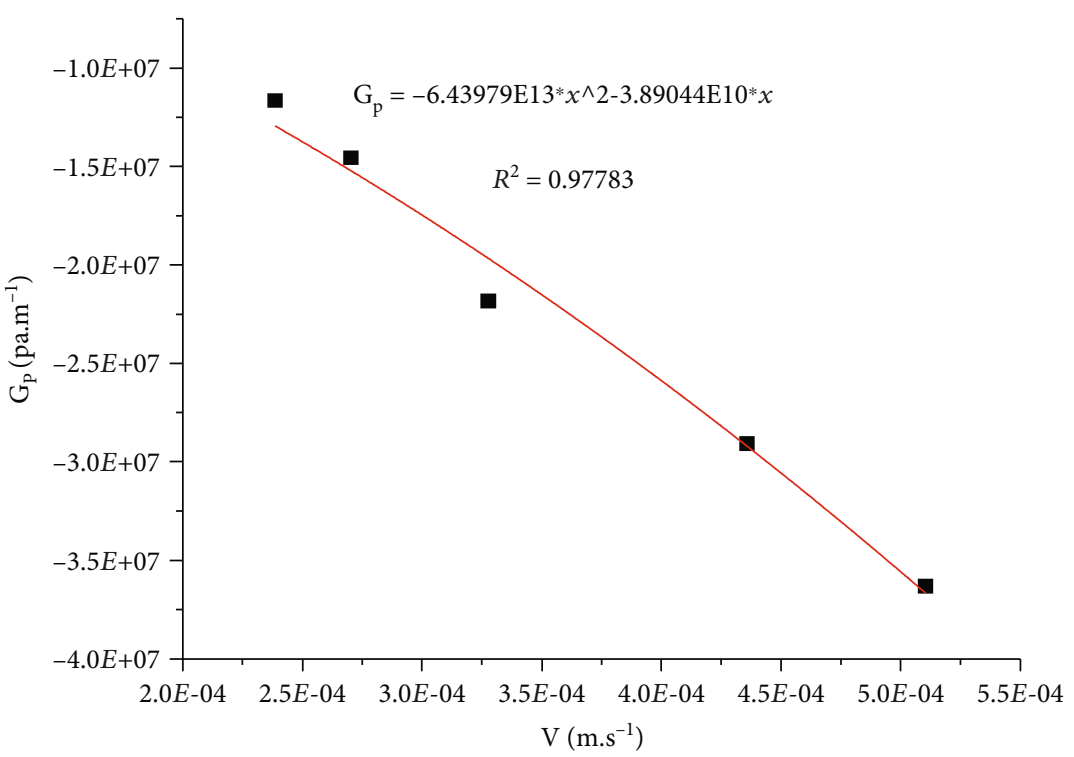

(a)

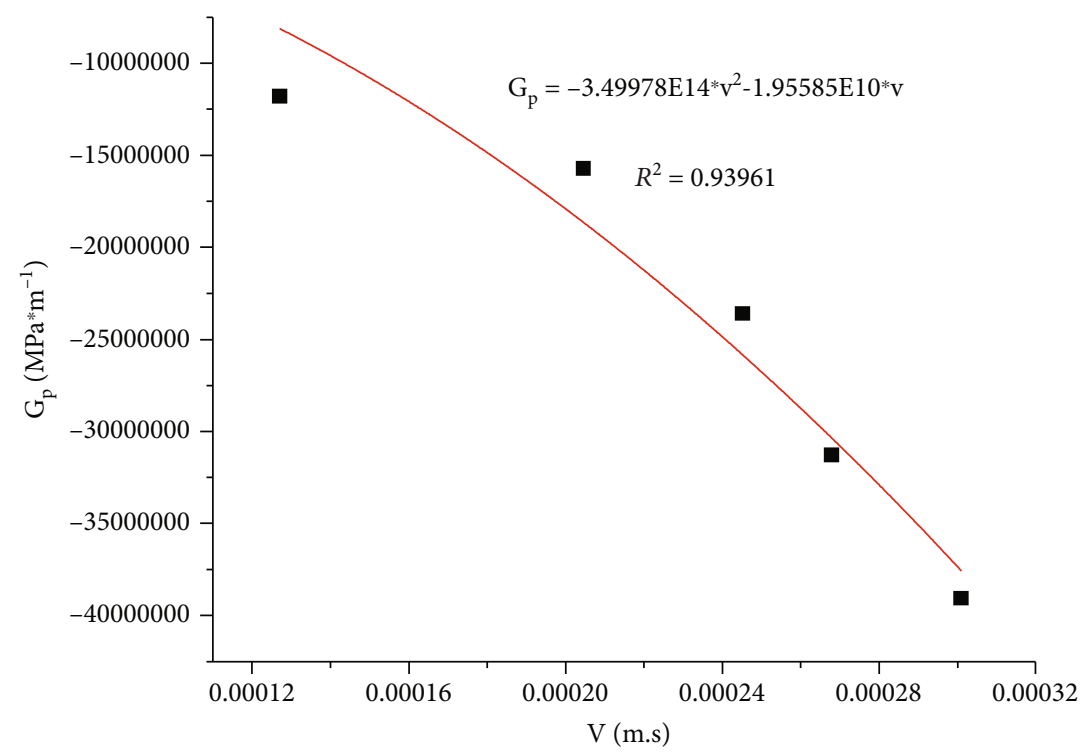

(b)

Figure 7: Continued. 


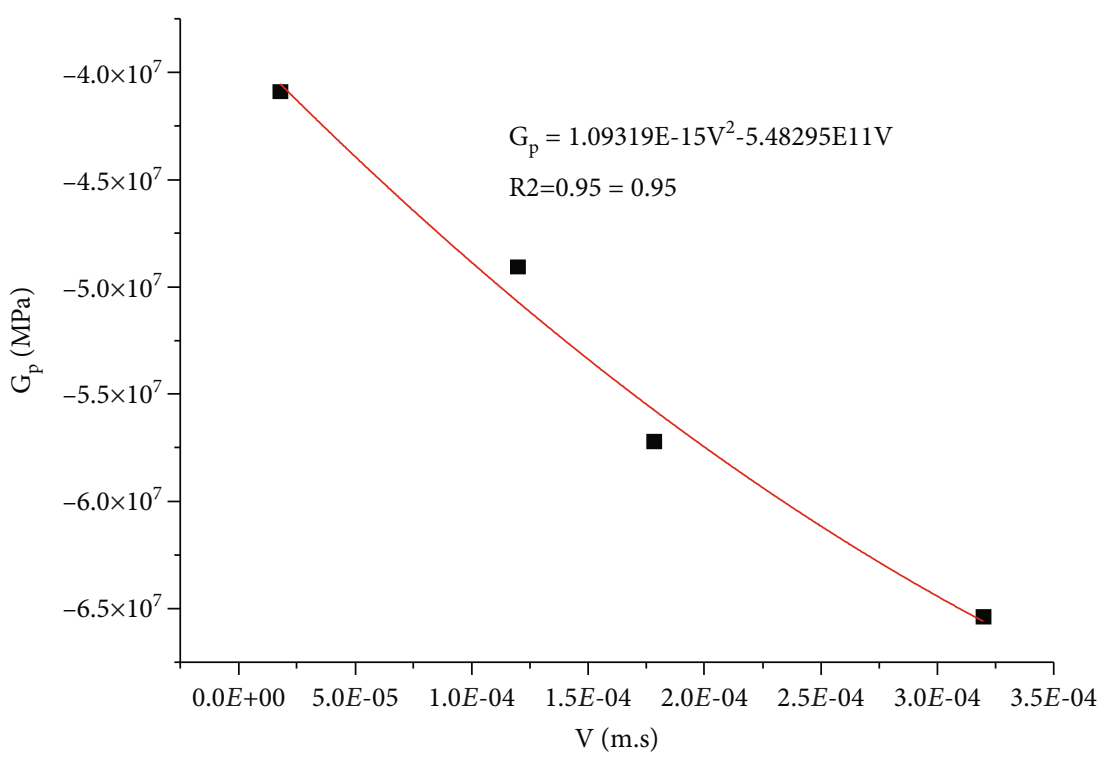

(c)

Figure 7: Fitted curves between $G_{p}$ and $V$ of the filling gangues with a particle size of $0 \sim 5 \mathrm{~mm}$ at different axial loads: (a) $4 \mathrm{MPa}$, (b) $6 \mathrm{MPa}$, and (c) $8 \mathrm{MPa}$.

the meantime, the inner channels in the bulk filling materials also changed under changing axial load and the inner water-diversion fracture channels underwent dynamic change. This can lay foundation for investigating the seepage characteristics of the bulk filling materials with different particle sizes.

By fitting the pressure gradient generated under different hydraulic pressures $G_{P}$ and the seepage velocity $V$ at a fixed axial load with non-Darcy Law that satisfies the Forchheimer formula, the permeability $k$ and the non-Darcy permeability factor $\beta$ in the formula can be obtained, as the fitted curves shown in Figures 7-10.

Figures 5-10 show the fitted curves between the pressure gradient under different hydraulic pressures $G_{P}$ and the seepage velocity $V$ for different sizes of gangues at different axial loads. Because of the limited measuring range of the flowmeter in the present experiment, the flow rate of large-size gangues at a small axial load exceeded the measuring range, while small-size gangues were compacted under a large axial load, resulting in 0 flow rate at different hydraulic pressures. Therefore, the permeability parameters cannot be obtained via fitting. Permeability parameters of gangue with different particle sizes are shown in Table 6.

In consideration of the restriction in the measuring range of the flowmeter, some seepage characteristics cannot be quantitatively analyzed but qualitatively measured. According to the practical condition in the field, the flow rate still equaled to 0 at a hydraulic pressure of $5 \sim 7 \mathrm{MPa}$, suggesting excellent water-resisting performance.

It can also be observed in Figures 5-10 that the pressure gradient and the flow velocity at a low axial load approximately followed linear relation. Moreover, nonlinearity was enhanced with the increasing axial load. At the beginning of axial load, the bulk filling materials were loose with large seepage discharge. Next, as the axial load increased gradually, the compaction velocity of pores in the bulk filling materials was great; accordingly, the change of pressure gradient can be described in a quadratic pattern. For the gangues within a same size range, the permeability dropped steadily with the increasing axial load. To be specific, the permeability remained between $10 E-14 \mathrm{~m}^{2}$ and $10 E-15$ $\mathrm{m}^{2}$ at an axial load of $4 \sim 10 \mathrm{MPa}$.

Next, it can be observed from the fitted curves between $G_{P}$ and $V$ that the non-Darcy permeability factor can be negative or positive, with constantly increasing the absolute value in the range of $10 E 10 \sim 10 E 12 \mathrm{~m}^{-1}$. The non-Darcy factor is more inclined to be positive for small-size gangues. As the particle size increased, the non-Darcy factor dropped to be negative. Since the compaction degree of small-size gangues is high, the flow increased slowly with the increase of hydraulic pressure gradient. The large-size gangues showed a low compaction degree, in which pores were great and new seepage channels were easily formed with the increasing hydraulic pressure, thereby generating large seepage velocity. After the experiments, the pictures were taken from the bottom of the filling body, as the pictures shown in Figure 11.

As shown in Figure 11, small-size gangues were more tightly compacted after loading, accompanied with more uniform pore distribution. By contrast, large-size gangues showed poor compaction effect after loading, accompanied with nonuniform pore distribution. It can also be found in the unloading process that the gangues in the upper part were small in size but were great in the lower part. Additionally, the crushing degree of the lower gangues was low. Next, the permeability should be below $10 E-15$ and non-Darcy factors should be above $10 E 12$ so as to achieve favorable water-resisting performance. 


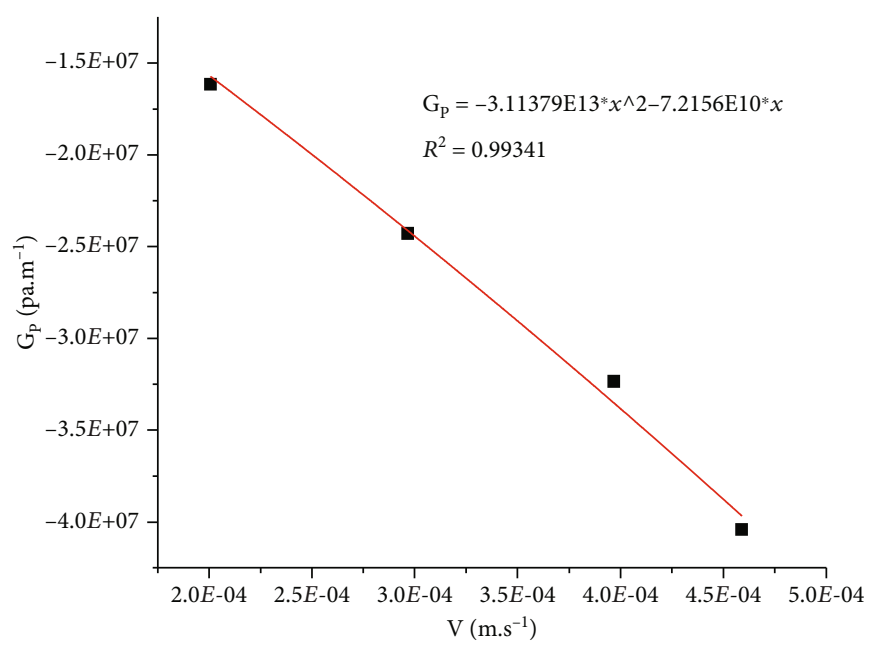

(a)

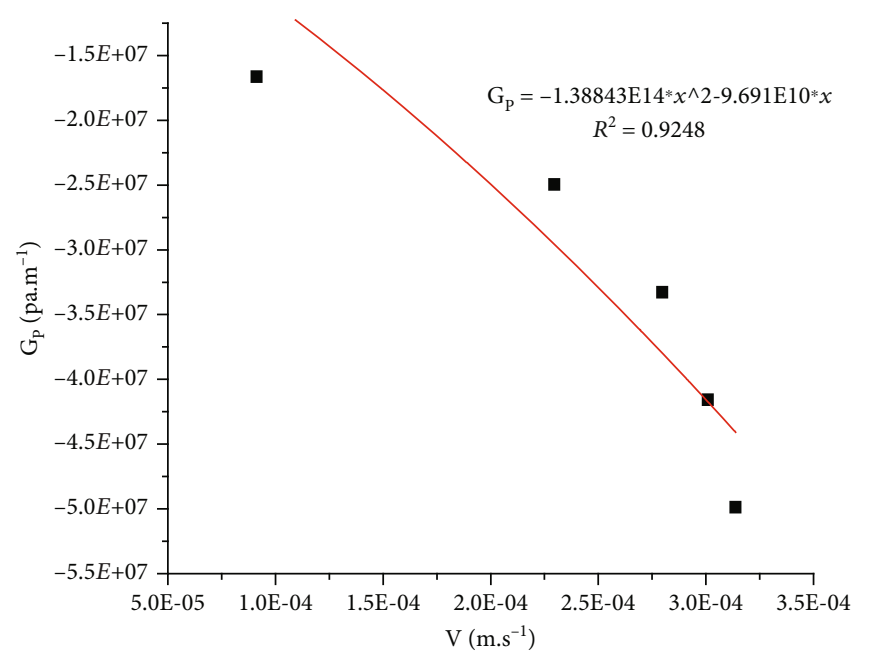

(b)

Figure 8: Fitted curves between $G_{p}$ and $V$ of the filling gangues with a particle size of $5 \sim 10 \mathrm{~mm}$ at different axial loads: (a) $6 \mathrm{MPa}$ and (b) $8 \mathrm{MPa}$.

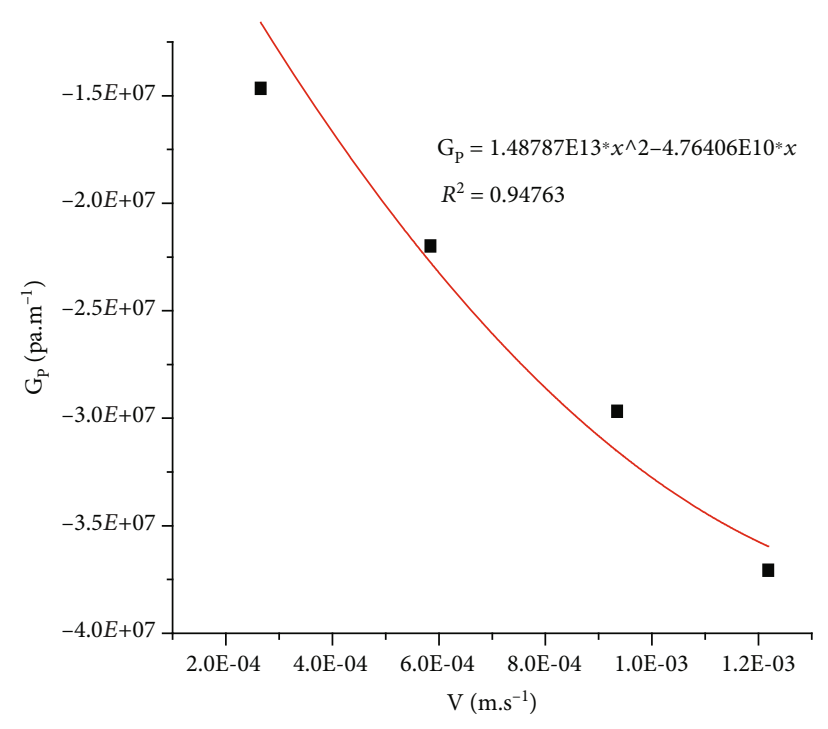

(a)

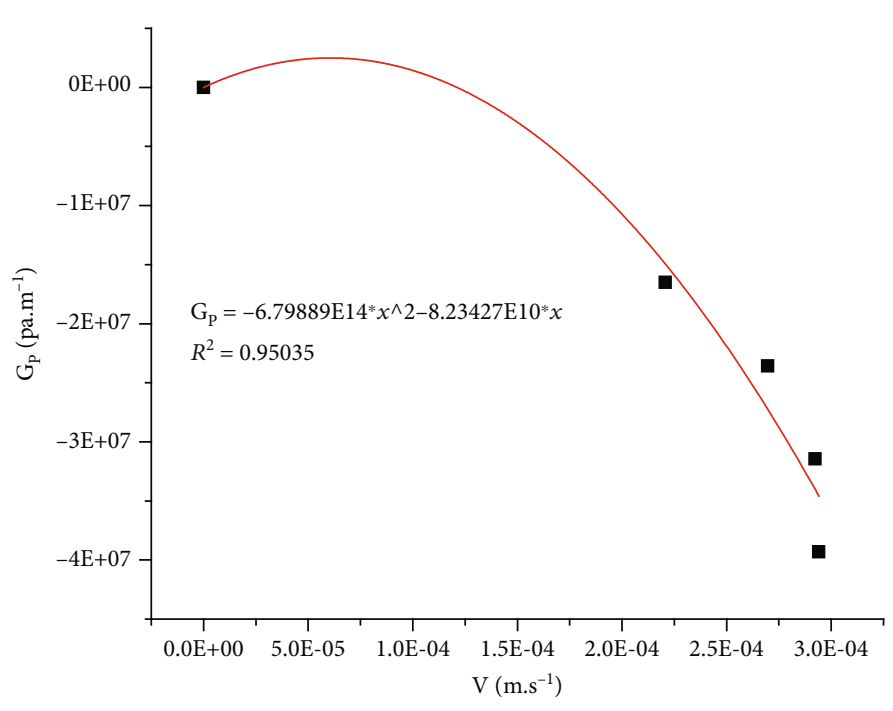

(b)

Figure 9: Fitted curves between $G_{p}$ and $V$ of the filling gangues with a particle size of $10 \sim 15 \mathrm{~mm}$ at different axial loads: (a) $6 \mathrm{MPa}$ and (b) $8 \mathrm{MPa}$.

\section{Discussions}

As stated above, the effects of the particle size of gangues on seepage discharge and permeability parameters under different axial loads and hydraulic pressures were examined in depth. Next, the seepage rules in different sizes of gangues (0 5 $\mathrm{mm}, 5 \sim 10 \mathrm{~mm}, 10 \sim 15 \mathrm{~mm}$, and $15 \sim 20 \mathrm{~mm})$ under an axial load of $6 \mathrm{MPa}$ and a hydraulic pressure of $4 \mathrm{MPa}$ were simulated for gaining in-depth knowledge of the effect of the particle size on seepage behaviors. Meanwhile, the variations of displacement, porosity, permeability, and flow velocity of different sizes of gangues and hydraulic pressure in the seep- age process were simulated. The detailed simulation process is described below.

According to the present simulation results, under an axial load of $6 \mathrm{MPa}$ and a hydraulic pressure of $4 \mathrm{MPa}$, the equivalent Young modulus and the Poisson's ratio of the filling gangues with a size range of $0 \sim 5 \mathrm{~mm}$ equaled to $0.6 \mathrm{GPa}$ and 15 , respectively.

When the axial load and the hydraulic pressure were fixed at $6 \mathrm{MPa}$ and $4 \mathrm{MPa}$, the equivalent Young modulus and the Poisson's ratio of the filling gangues with a size range of $5 \sim 10 \mathrm{~mm}$ in this simulation equaled to $0.5 \mathrm{GPa}$ and 16, respectively. The cloud charts of the changes of 


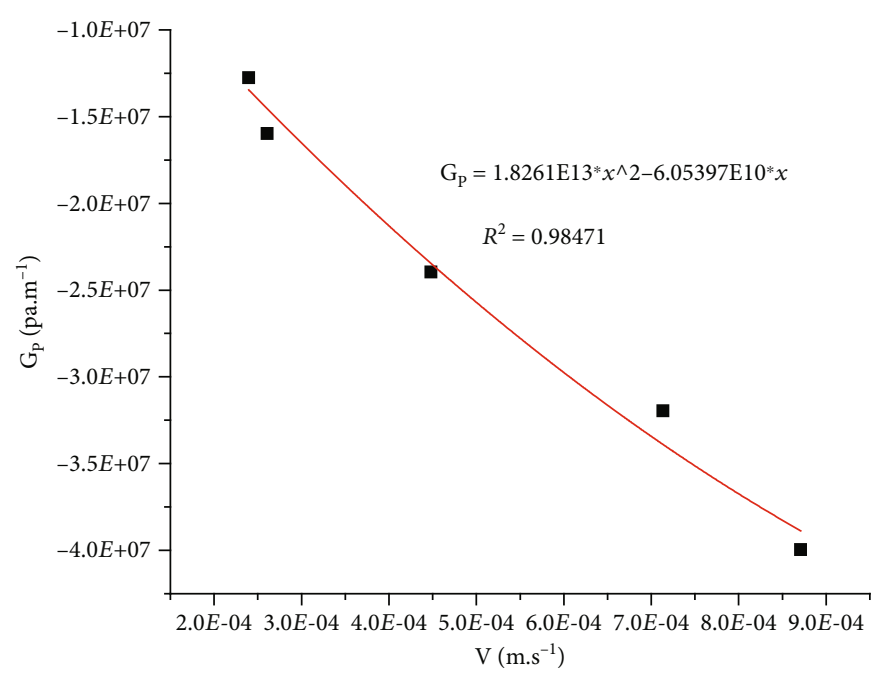

(a)

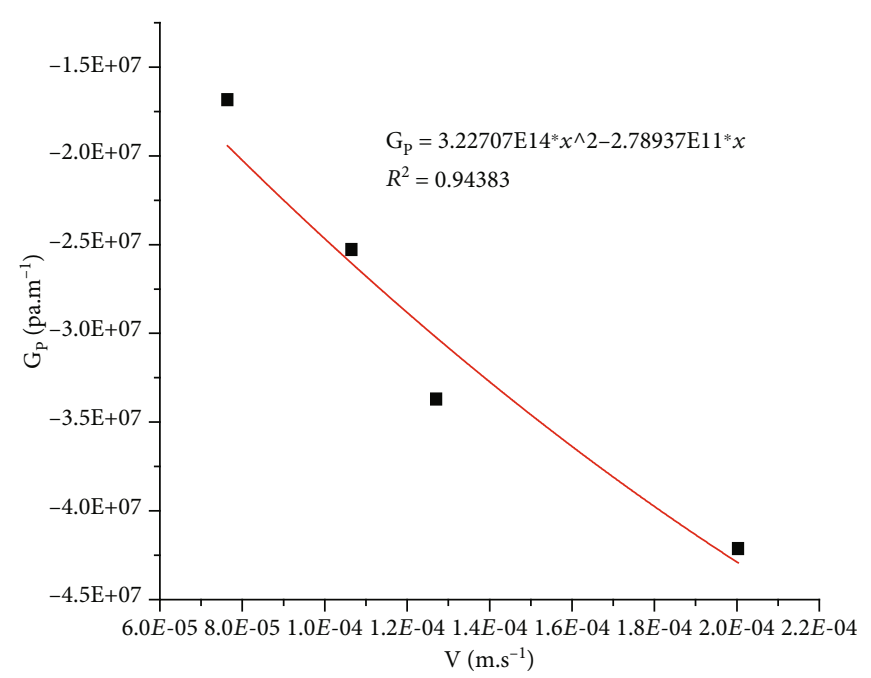

(b)

Figure 10: Fitted curves between $G_{p}$ and $V$ of the filling gangues with a particle size of $0 \sim 5 \mathrm{~mm}$ at different axial loads: (a) $8 \mathrm{MPa}$ and (b) $10 \mathrm{MPa}$.

TABle 6: Permeability parameters of the filling gangues with different sizes.

\begin{tabular}{|c|c|c|c|c|c|c|}
\hline \multirow{2}{*}{ Particle size $(\mathrm{mm})$} & \multirow{2}{*}{ Permeability parameters } & \multicolumn{5}{|c|}{ Axial load $(\mathrm{MPa})$} \\
\hline & & 4 & 6 & 8 & 10 & 16 \\
\hline \multirow{2}{*}{$0 \sim 5$} & Permeability $\left(\mathrm{m}^{2}\right)$ & $2.57 E-14$ & $1.11 E-14$ & $1.82 E-15$ & - & - \\
\hline & Non-Darcy factor $\left(\mathrm{m}^{-1}\right)$ & $6.44 E+10$ & $3.50 E+11$ & $-1.09 E+12$ & - & - \\
\hline \multirow{2}{*}{$5 \sim 10$} & Permeability $\left(\mathrm{m}^{2}\right)$ & - & $1.75 E-14$ & $1.02 E-14$ & $2.30 E-15$ & - \\
\hline & Non-Darcy factor $\left(\mathrm{m}^{-1}\right)$ & - & $6.83 E+10$ & $1.41 E+11$ & $1.46 E+12$ & - \\
\hline \multirow{2}{*}{$10 \sim 15$} & Permeability $\left(\mathrm{m}^{2}\right)$ & - & $2.10 E-14$ & $1.21 E-14$ & - & - \\
\hline & Non-Darcy factor $\left(\mathrm{m}^{-1}\right)$ & - & $-1.49 E+10$ & $6.80 E+11$ & - & - \\
\hline \multirow{2}{*}{$15 \sim 20$} & Permeability $\left(\mathrm{m}^{2}\right)$ & - & - & $1.65 E-14$ & $3.78 E-15$ & - \\
\hline & Non-Darcy factor $\left(\mathrm{m}^{-1}\right)$ & - & - & $-1.83 \mathrm{E}+10$ & $-2.65 E+11$ & - \\
\hline
\end{tabular}

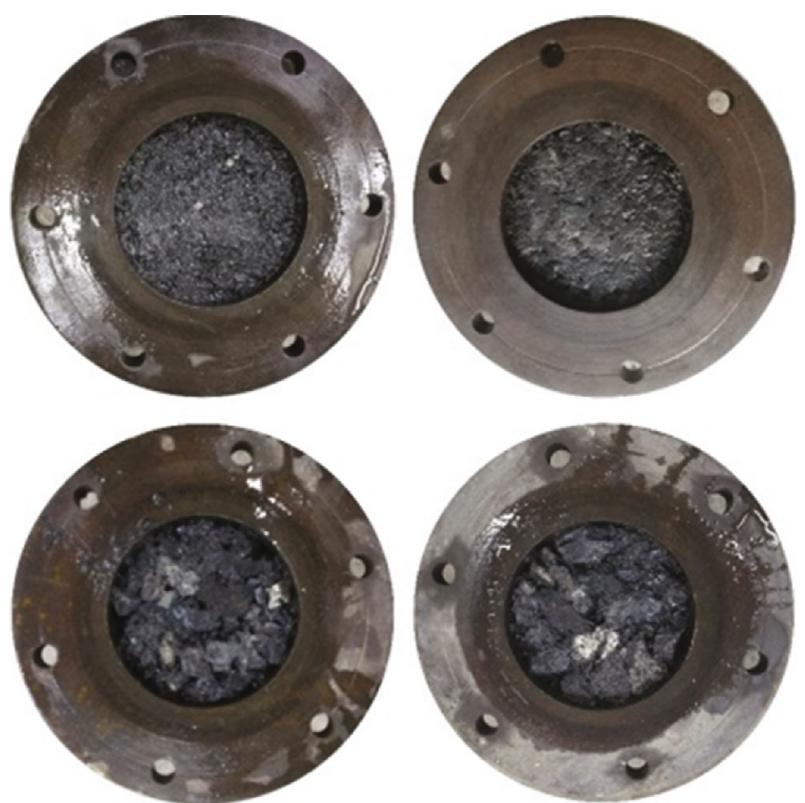

Figure 11: Pictures after the seepage in different sizes of gangues. displacement, porosity, permeability, flow velocity, and hydraulic pressure under the stress and particle size conditions were plotted, as shown in Figure 12.

For the gangues with a size range of $10 \sim 15 \mathrm{~mm}$, when the axial load and the hydraulic pressure were fixed at $6 \mathrm{MPa}$ and $4 \mathrm{MPa}$, the equivalent Young modulus and the Poisson's ratio were $0.7 \mathrm{GPa}$ and 26.5, respectively. Based on COMSOL simulation results, the cloud charts of the changes of displacement, porosity, permeability, flow velocity, and hydraulic pressure under the stress and particle size conditions were plotted, as shown in Figure 13.

Similarly, the simulation was performed on the gangues with a size range of $15 \sim 20 \mathrm{~mm}$ at an axial load of $6 \mathrm{MPa}$ and a hydraulic pressure of $4 \mathrm{MPa}$. According to the simulation results, the equivalent Young modulus and the Poisson's ratio equaled to $0.75 \mathrm{GPa}$ and 28 , respectively. Figure 14 reflects the changes of displacement, porosity, permeability, flow velocity, and hydraulic pressure during the seepage process in the gangues with a size range of $15 \sim 20 \mathrm{~mm}$. 


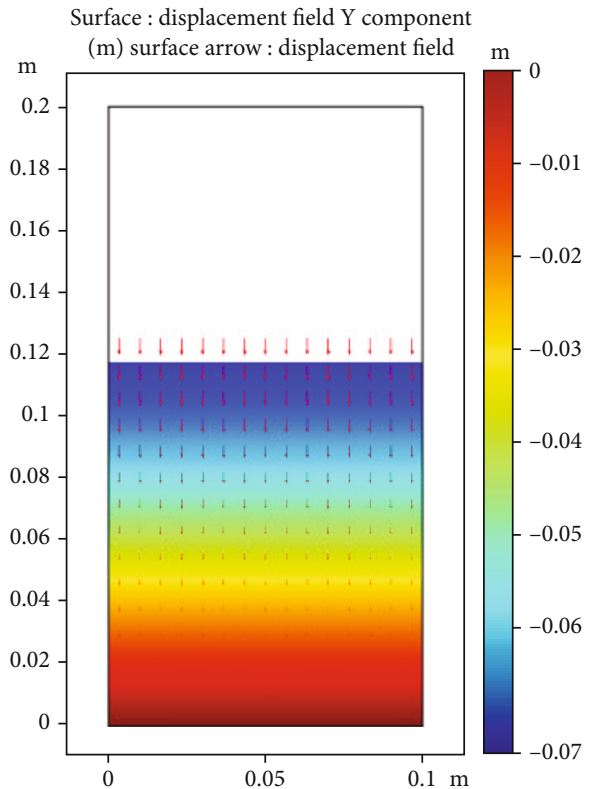

(a) Displacement

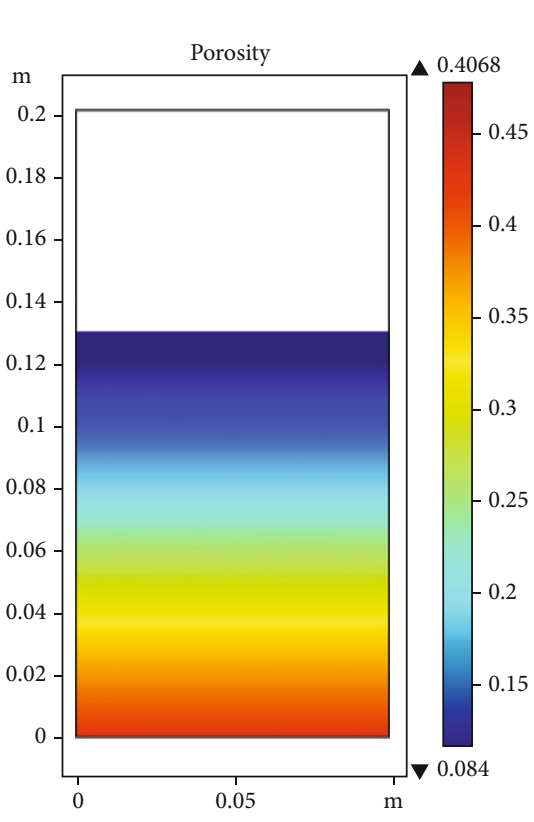

(b) Porosity

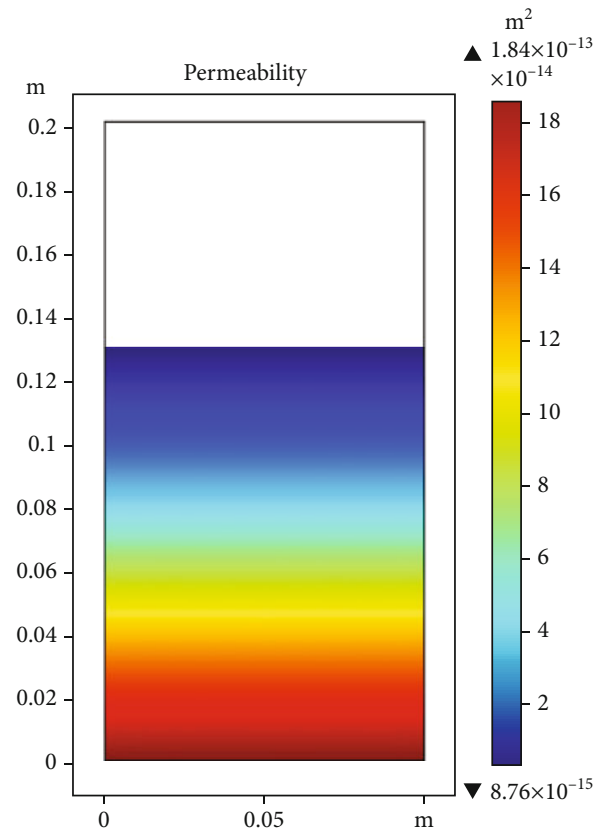

(c) Permeability

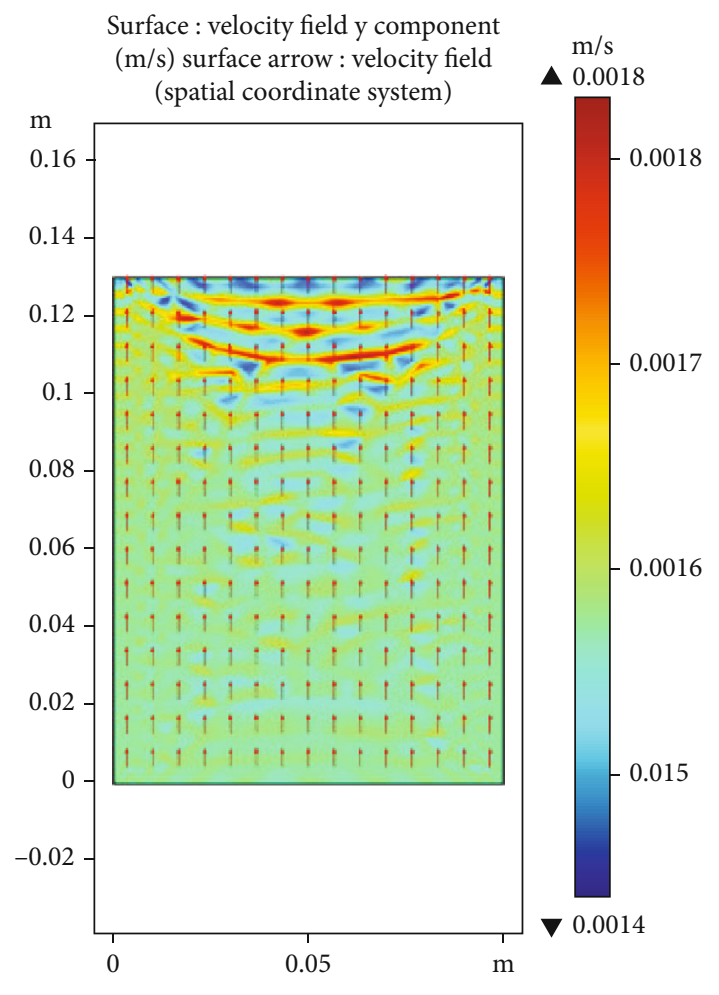

(d) Flow velocity

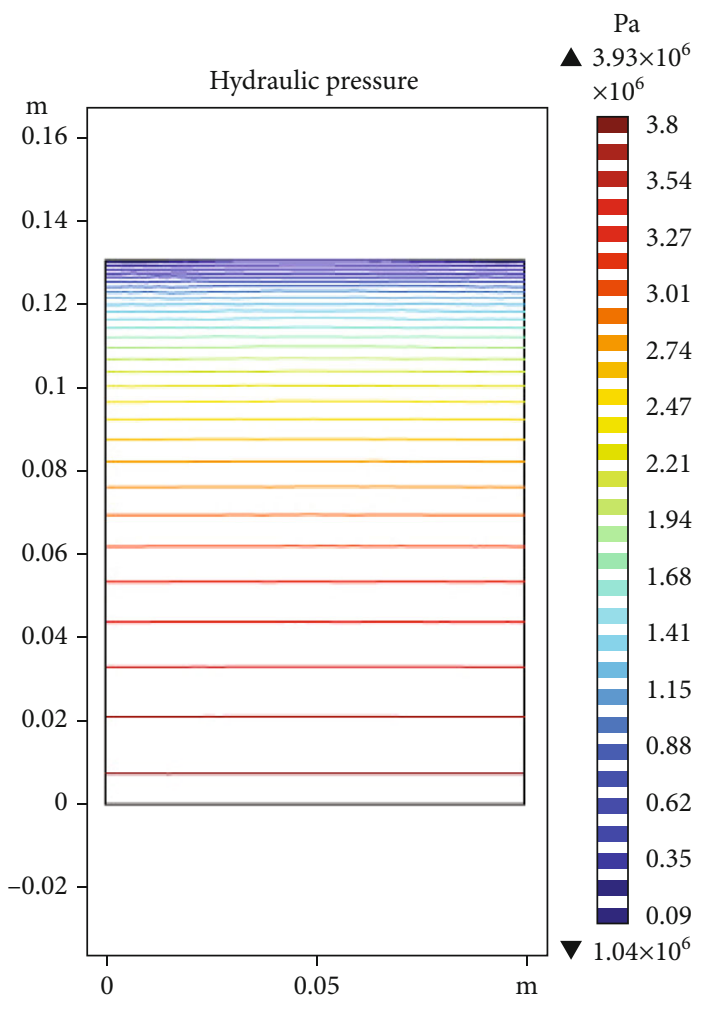

(e) Hydraulic pressure

FIGURE 12: Seepage rules in the gangues with a size range of $5 \sim 10 \mathrm{~mm}$.

As shown in Figures 14-15, the gangues with a larger particle size underwent less displacement. The displacement of the gangues with a particle size range of $5 \sim 10 \mathrm{~mm}$ reached a maximum of $84.8 \mathrm{~mm}$, while the displacements of the gangues within the other size ranges were $63 \mathrm{~mm}$, $75.22 \mathrm{~mm}$, and $75.9 \mathrm{~m}$, respectively. Under a same axial load, the porosity of the gangues with larger particle size was greater. The porosity of the gangues with a particle size range of $15 \sim 20 \mathrm{~mm}$ was greatest, accompanied with the greatest permeability. Accordingly, the distribution of hydraulic pressure in the gangues with a larger size was more uniform. The simulation results with COMSOL software fit 


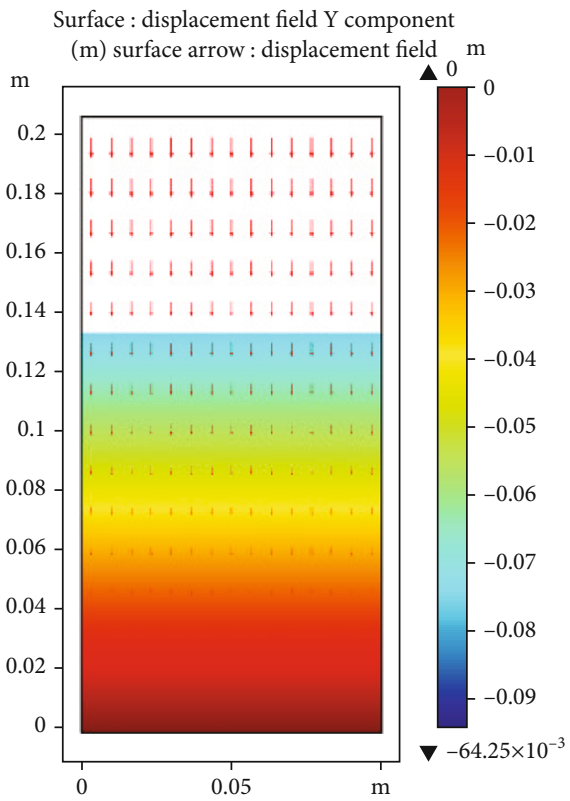

(a) Displacement

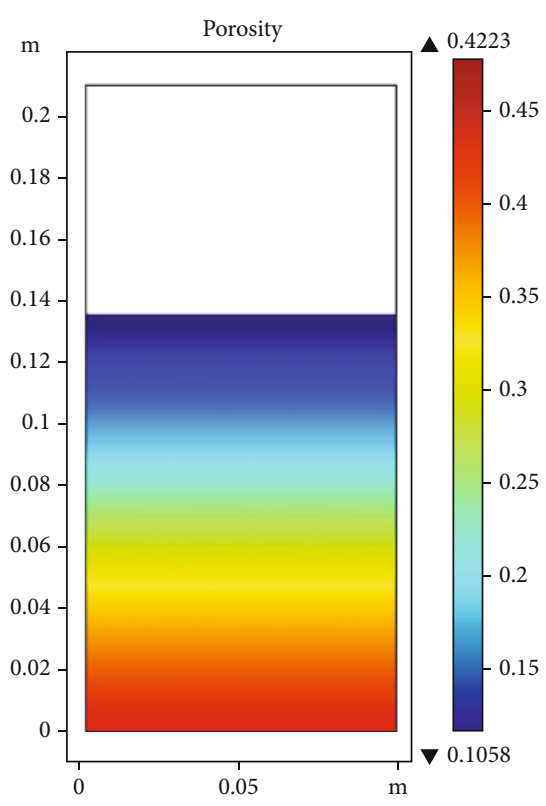

(b) Porosity

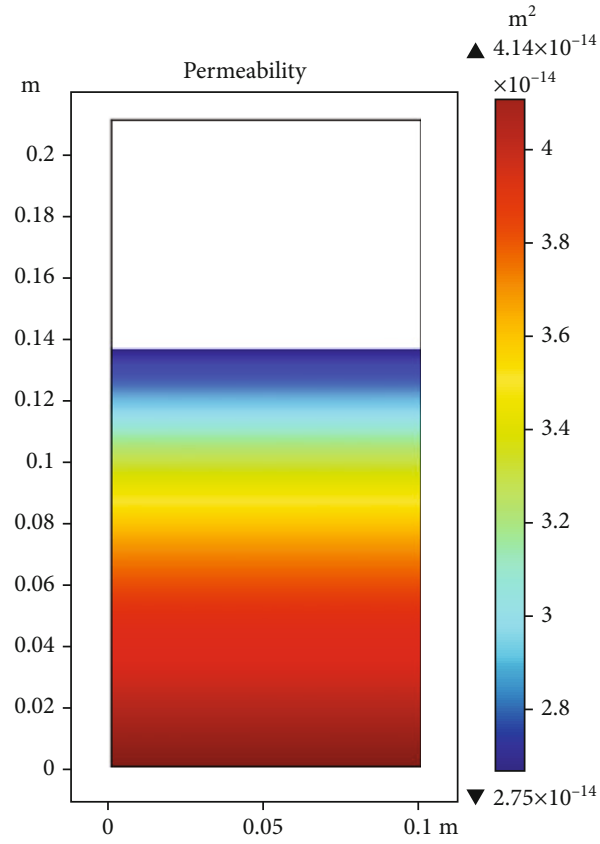

(c) Permeability

Surface : velocity field y component $(\mathrm{m} / \mathrm{s})$ surface arrow : velocity field $\mathrm{m} / \mathrm{s}$

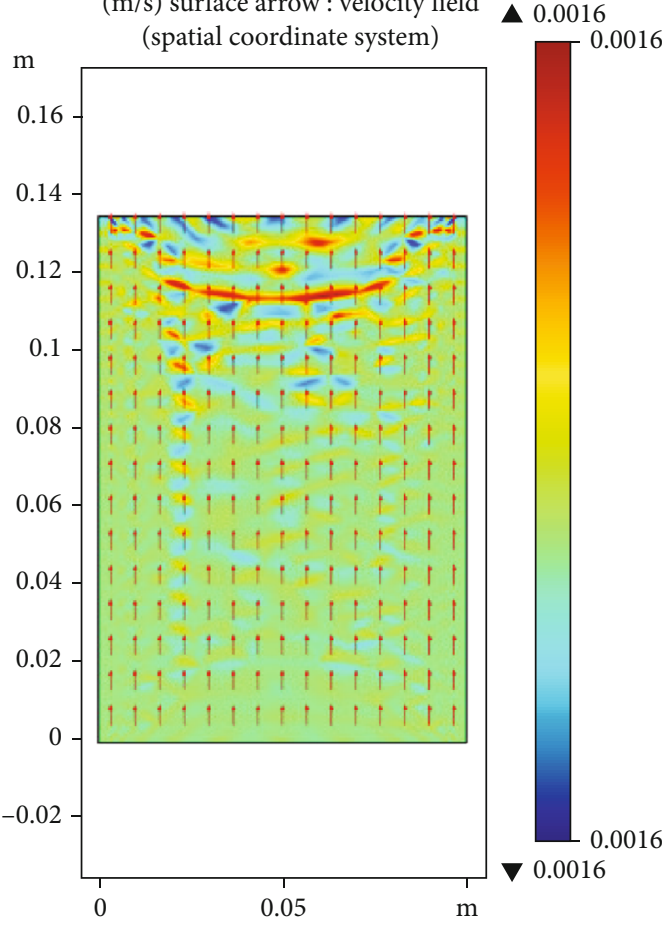

(d) Flow velocity

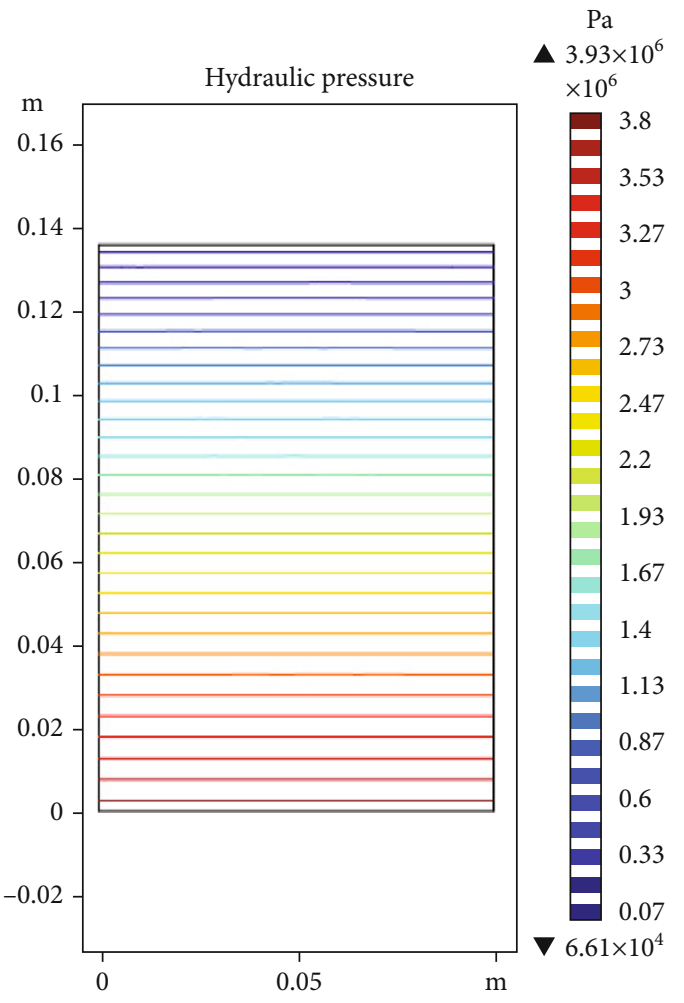

(e) Hydraulic pressure

FIGURE 13: Seepage rules in the gangues with a size range of $10 \sim 15 \mathrm{~mm}$. 


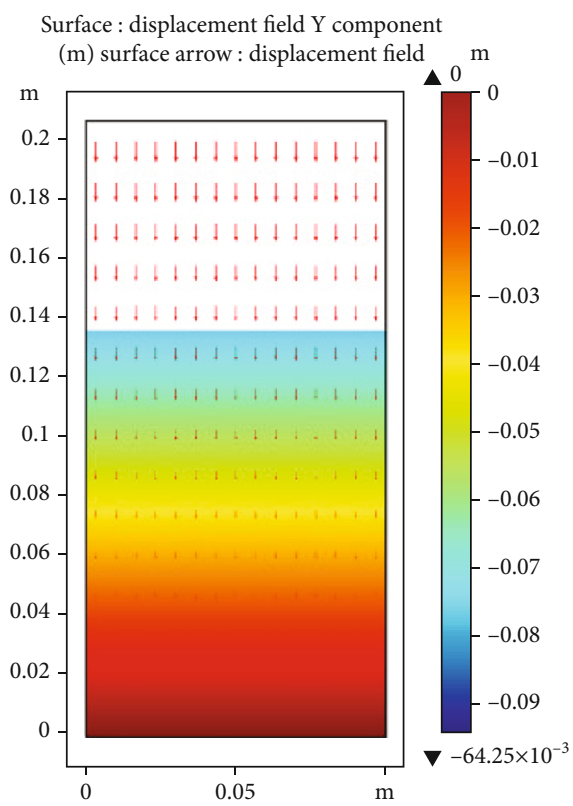

(a) Displacement

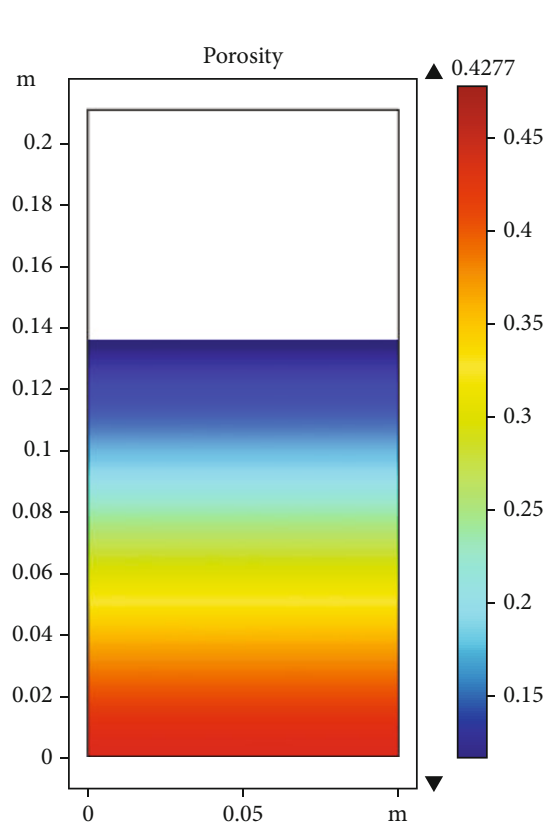

(b) Porosity

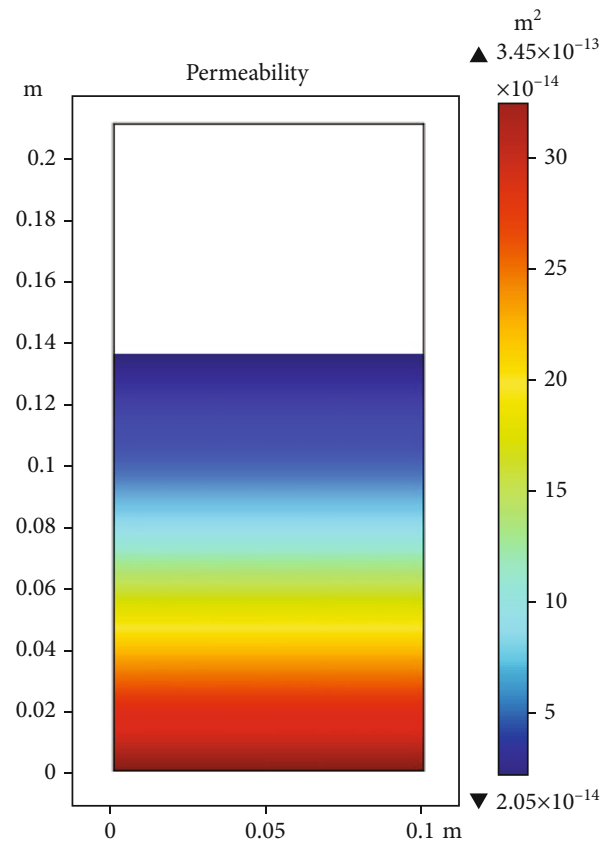

(c) Permeability

Surface : velocity field y component $(\mathrm{m} / \mathrm{s})$ surface arrow : velocity field

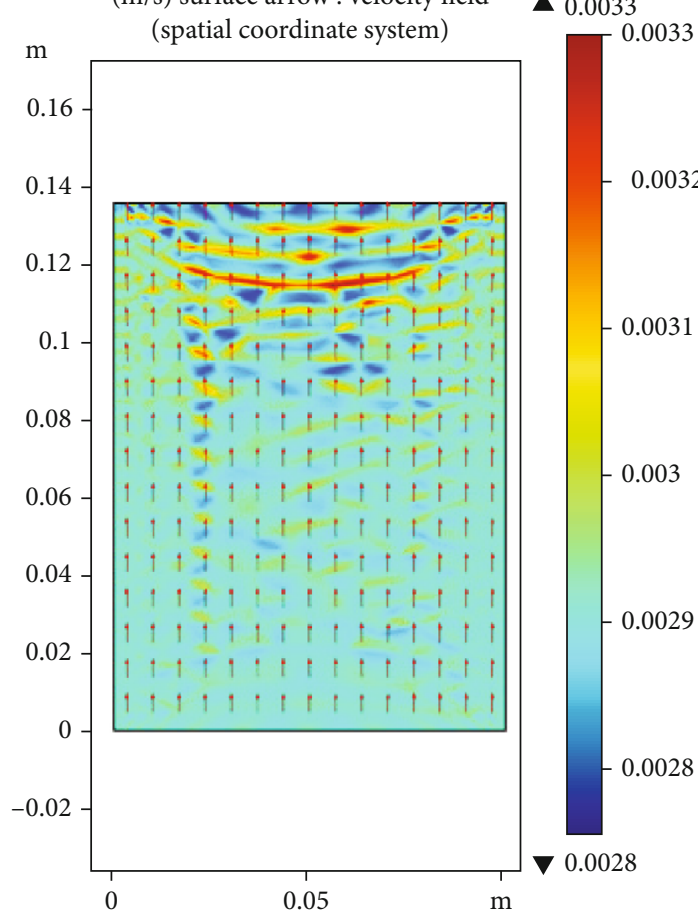

(d) Flow velocity

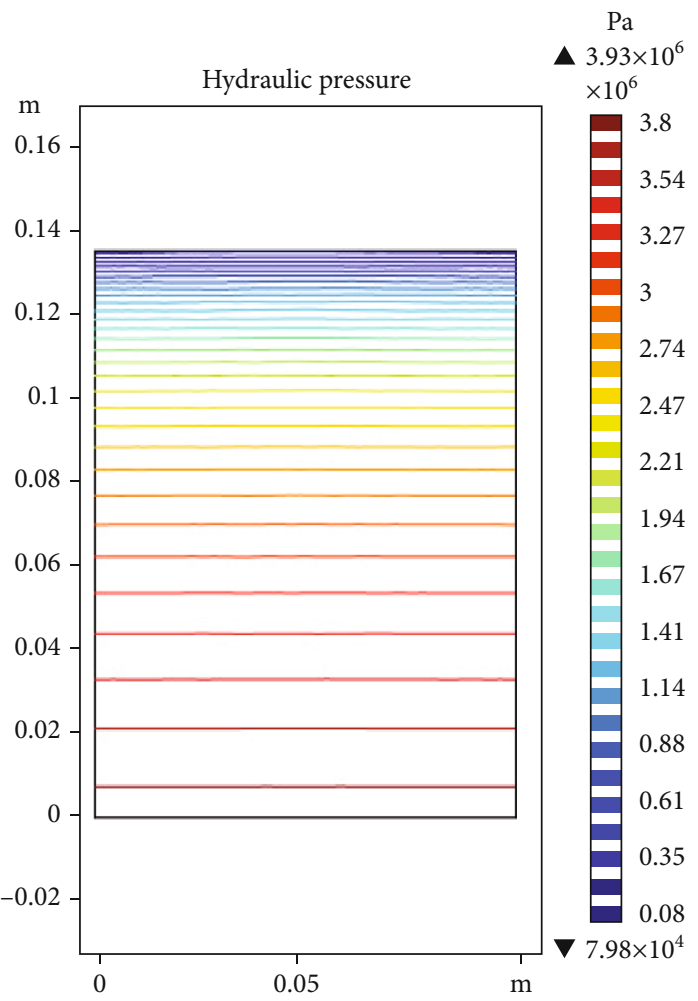

(e) Hydraulic pressure

Figure 14: Seepage rules in the gangues with a size range of $15 \sim 20 \mathrm{~mm}$. 


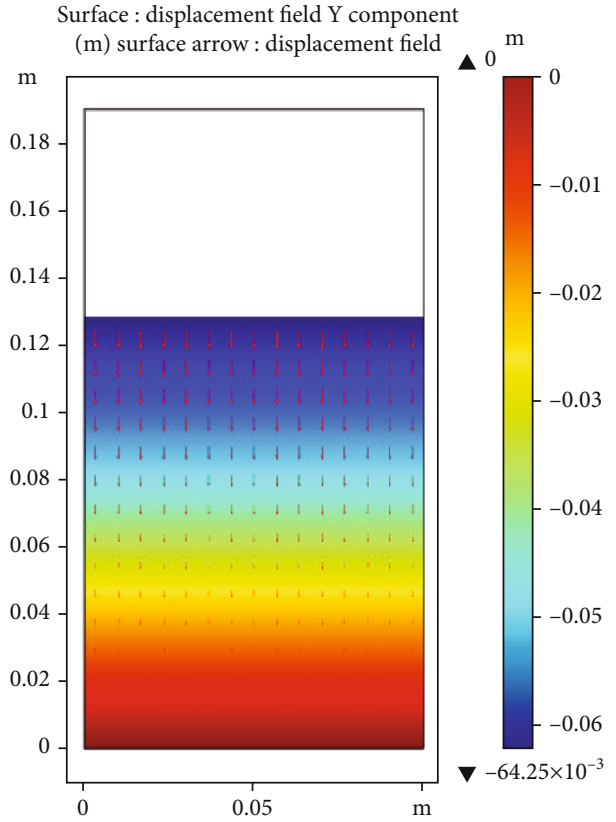

(a) Displacement

Surface : velocity field y component $(\mathrm{m} / \mathrm{s})$ surface arrow : velocity field (spatial coordinate system)

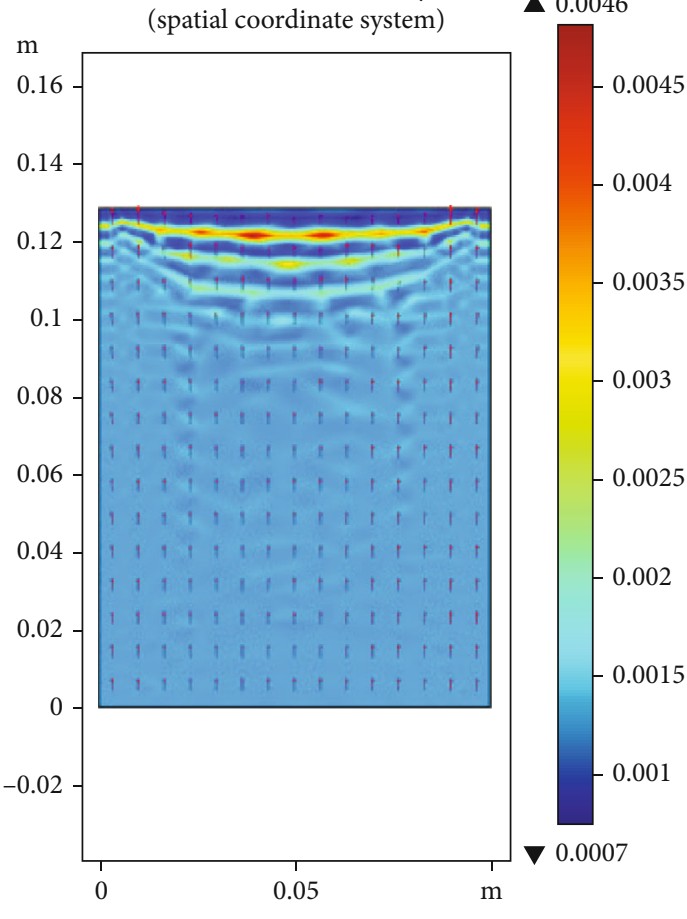

(d) Flow velocity

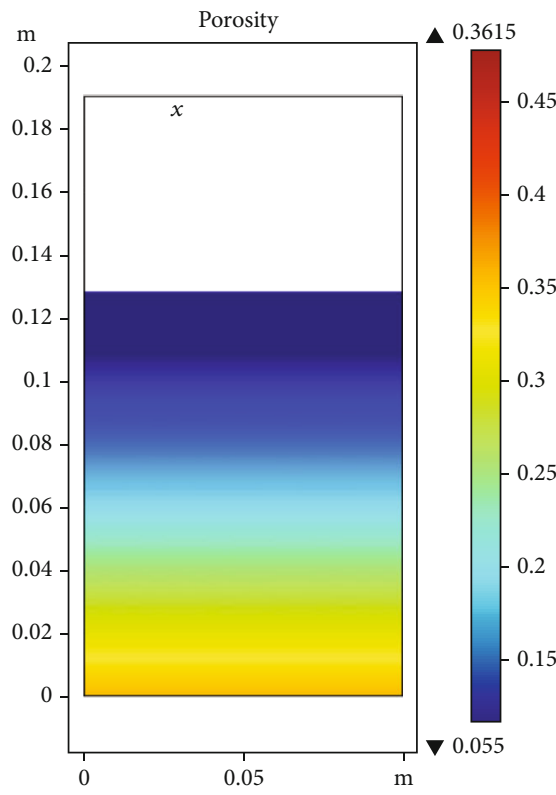

(b) Porosity

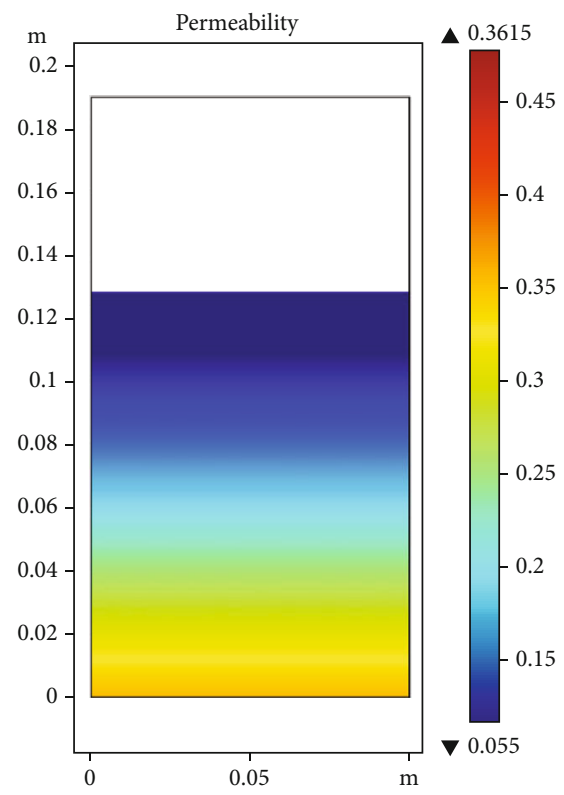

(c) Permeability

$\mathrm{Pa}$

A $5.92 \times 10^{6}$

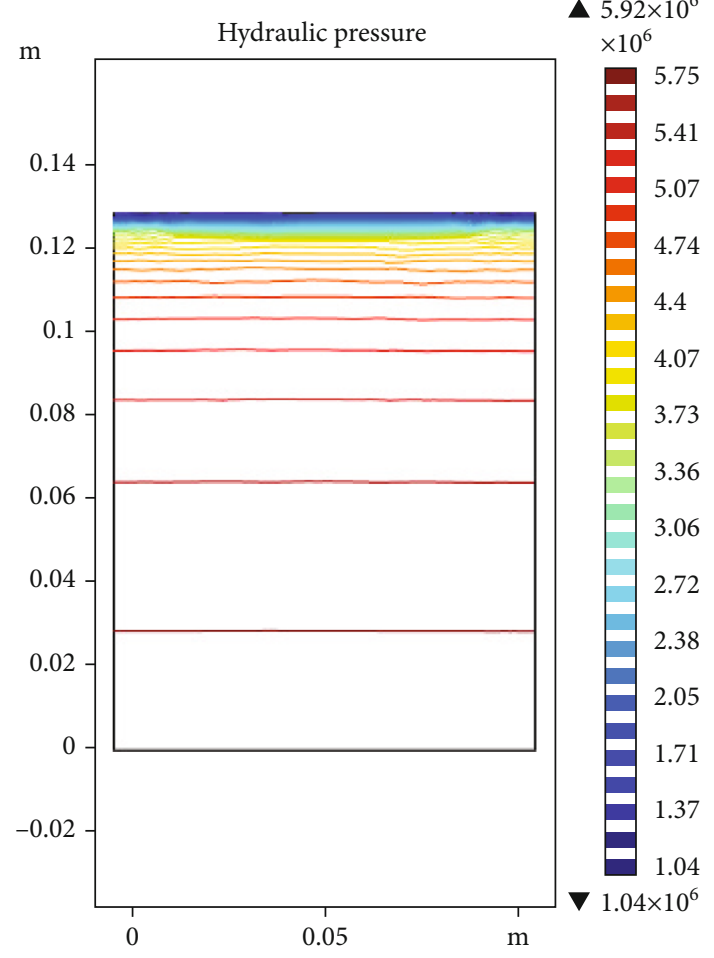

(e) Hydraulic pressure

Figure 15: Seepage rules in the gangues with a size range of $0 \sim 5 \mathrm{~mm}$. 


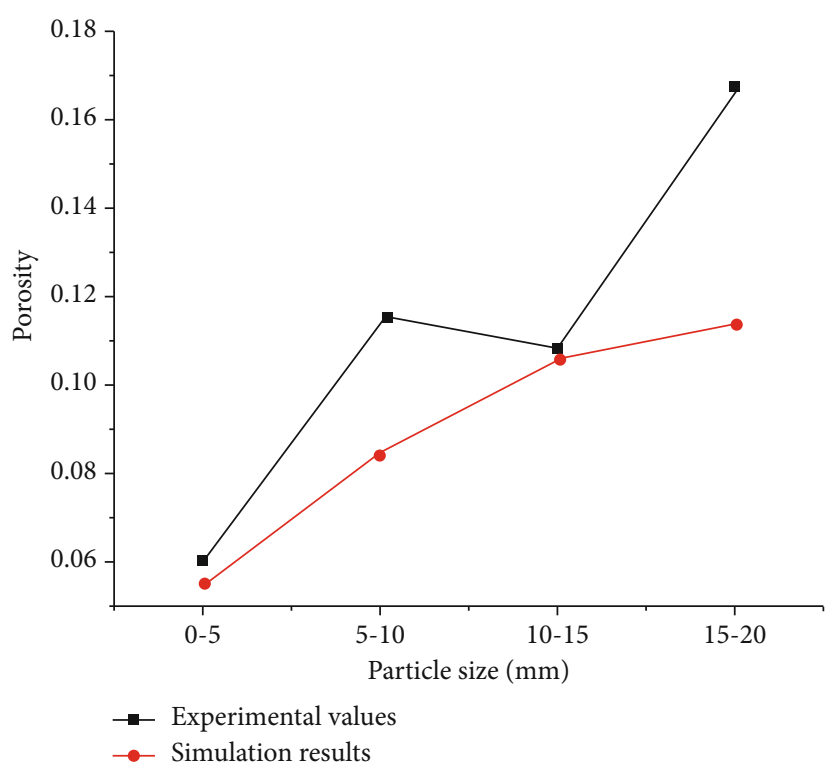

(a) Porosity

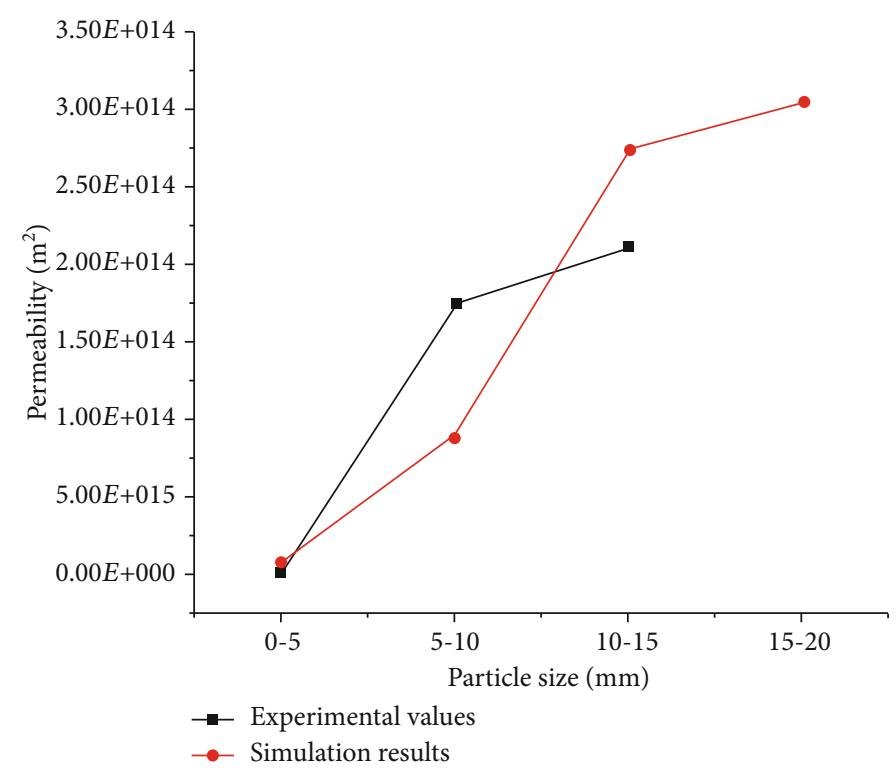

(b) Permeability

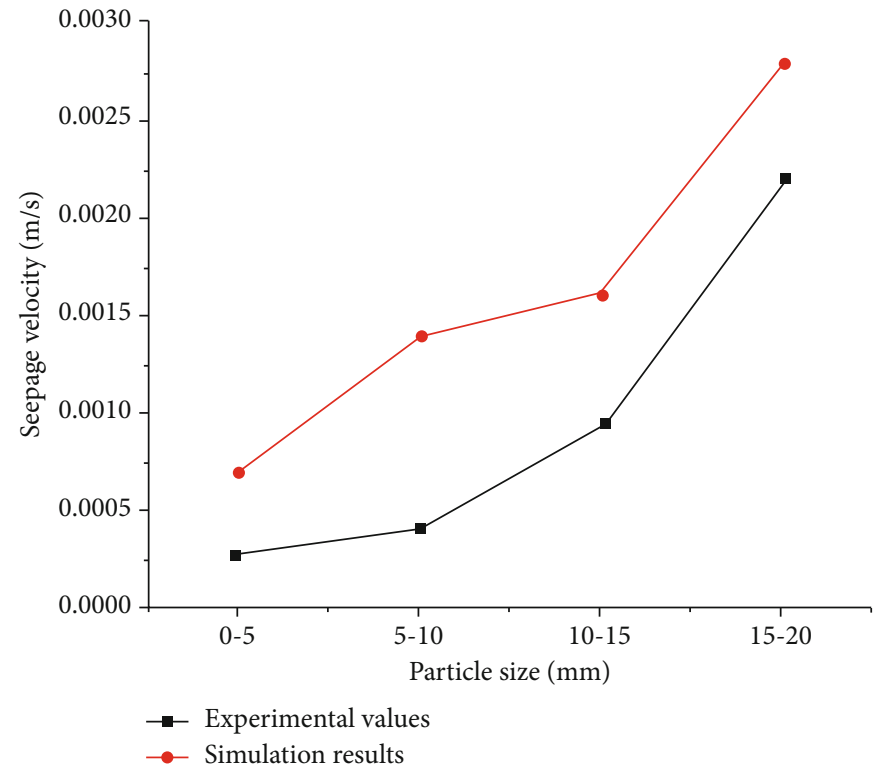

(c) Seepage velocity

FIGURE 16: Comparison between the experimental and numerical simulation data for different sizes of gangues.

well with the data in seepage experiment, validating the reliability of the present experiment.

Figure 16 compares the experimentally measured porosities, permeabilities, and seepage velocities of different sizes of gangues with the numerical simulation data.

Apparently, the seepage velocity curves between experimental and the simulation results show higher coincidence than the other two curves. Moreover, the porosity, the permeability, and the seepage velocity of the gangues increased gradually with the increasing particle size.

\section{Conclusions}

This study experimentally investigated the fundamental physical and mechanical properties of gangues and the effects of the particle size on the seepage discharge and the permeability parameters in the gangues with different sizes under different axial loads and hydraulic pressures and revealed the variations of the flow rate with axial load and hydraulic pressure in the gangues within a same size range. Finally, the effects of the particle size on the seepage rules of gangues were concluded via COMSOL numerical simulation for validating the reliability of the present experiment. The following conclusions can be drawn.

(1) Firstly, some fundamental physical and mechanical properties of the bulk filling materials were measured. The density of the bulk filling gangues under natural condition was $2.08 \mathrm{~g} / \mathrm{cm}^{3}$; after soaking, the saturated density changed to be $2.12 \mathrm{~g} / \mathrm{cm}^{3}$. The accumulation 
densities of the filling gangues with different size ranges $\quad(0 \sim 5 \mathrm{~mm}, \quad 5 \sim 10 \mathrm{~mm}, \quad 10 \sim 15 \mathrm{~mm}$, and $15 \sim 20 \mathrm{~mm}$ ) were $1.475 \mathrm{~g} / \mathrm{cm}^{3}, 1.409 \mathrm{~g} / \mathrm{cm}^{3}, 1.398 \mathrm{~g} /$ $\mathrm{cm}^{3}$, and $1.395 \mathrm{~g} / \mathrm{cm}^{3}$, respectively. Meanwhile, the initial porosities of the filling gangues with different size ranges were $0.34,0.42,0.43$, and 0.47 , respectively. The above analysis of fundamental physical and mechanical properties of gangues can provide insightful reference for later investigation of basic physical and mechanical behaviors during water seepage in the filling materials

(2) The effects of the particle size of gangues on water seepage discharges and permeability parameters at different axial loads and hydraulic pressures were also investigated in the laboratory. Considering that the bulk filling gangues are a kind of discontinuous media, the bulk filling materials were gradually compacted under increasing axial load, accompanied with the change of inner seepage channels. Meanwhile, as the hydraulic pressure increased steadily, water-diversion channels in the bulk filling materials increased, which also increased water seepage discharge. Under varying axial load and hydraulic pressure, the seepage trajectories of water in the bulk filling materials changed, which can provide reference for investigating the seepage characteristics in the bulk filling materials with different sizes

(3) Finally, the effects of the particle size on water seepage behaviors were simulated with COMSOL numerical simulation software. The seepage behaviors in gangues can be characterized by the displacement, the porosity, and the permeability of gangues as well as water flow velocity and hydraulic pressure. For the gangues with a size range of $5 \sim 10 \mathrm{~mm}$, the displacement of gangues reached a maximum of $84.8 \mathrm{~mm}$; moreover, hydraulic pressure distribution became more uniform with the increasing particle size, accompanied with a steady increase of porosity and permeability of gangue. The numerical simulation results with COMSOL fit well with the present experimental data, validating the reliability of the seepage experiment

\section{Data Availability}

The latest data used to support the findings of this study are included within the article.

\section{Conflicts of Interest}

None of the authors have any conflicts of interest.

\section{Acknowledgments}

This research was funded by the Postgraduate Research \& Practice Innovation Program of Jiangsu Province (KYCX21_2338).

\section{References}

[1] H. J. Li, R. Y. Long, and H. Chen, "Economic transition policies in Chinese resource-based cities: an overview of government efforts," Energy Policy, vol. 55, pp. 251-260, 2013.

[2] J. T. Chen, L. M. Yin, W. B. Sun, C. Lu, S. C. Zhang, and X. Z. Sun, "Development and application for new solid-fluid coupling similar material of deep floor aquifer," Chinese Journal of Rock Mechanics and Engineering, vol. 34, no. 2, pp. 39563964, 2015.

[3] H. Zhang, Y. Wang, R. X. Yang, and R. Z. Ye, "Modeling the effects of phosphate mining on groundwater at different stages of mine development," Mine Water and the Environment, vol. 37, no. 3, pp. 604-616, 2018.

[4] P. Y. Li, "Mine water problems and solutions in China," Mine Water and The Environment, vol. 37, no. 2, pp. 217-221, 2018.

[5] D. Ma, X. X. Miao, H. B. Bai et al., "Effect of mining on shear sidewall groundwater inrush hazard caused by seepage instability of the penetrated karst collapse pillar," Natural Hazards, vol. 82, no. 1, pp. 73-93, 2016.

[6] H. Bouwer, "Land subsidence and cracking due to groundwater depletiona," Groundwater, vol. 15, no. 5, pp. 358-364, 1977.

[7] Y. Xue, J. Liu, P. G. Ranjith, X. Liang, and S. Wang, "Investigation of the influence of gas fracturing on fracturing characteristics of coal mass and gas extraction efficiency based on a multi-physical field model," Journal of Petroleum Science and Engineering, vol. 206, article 109018, 2021.

[8] K. Ma, L. M. Yin, J. T. Chen, M. Chen, Z. Q. Wang, and B. Q. Cui, "Theoretical analysis on failure of water-resisting key strata in the floor by local high confined water in deep mining," Rock and Soil Mechanics, vol. 39, no. 9, pp. 3213-3222, 2018.

[9] D. Ma, H. Duan, W. Liu, X. Ma, and M. Tao, "Water-Sediment two-phase flow inrush hazard in rock fractures of overburden strata during coal mining," Mine Water and the Environment, vol. 39, no. 2, pp. 308-319, 2020.

[10] A. Karaman, P. J. Carpenter, and C. J. Booth, "Type-curve analysis of water-level changes induced by a longwall mine," Environmental Geology, vol. 40, no. 7, pp. 897-901, 2001.

[11] Y. Xue, T. Teng, F. Dang, Z. Ma, S. Wang, and H. Xue, "Productivity analysis of fractured wells in reservoir of hydrogen and carbon based on dual-porosity medium model," International Journal of Hydrogen Energy, vol. 45, no. 39, pp. 20240-20249, 2020.

[12] R. Gao, H. Yan, F. Ju, X. Mei, and X. Wang, "Influential factors and control of water inrush in a coal seam as the main aquifer," International Journal of Mining Science and Technology, vol. 28, no. 2, pp. 187-193, 2018.

[13] J. F. Hou, Z. P. Guo, W. Z. Liu, H. Yang, and W. W. Xie, "Study on damage model and damage evolution characteristics of backfill with prefabricated fracture under seepage-stress coupling," Advances in Materials Science and Engineering, vol. 2020, 11 pages, 2020.

[14] J. M. Li, Y. L. Huang, and M. Qiao, "Effects of water soaked height on the deformation and crushing characteristics of loose gangue backfill material in solid backfill coal mining," Processes, vol. 6, no. 6, p. 64, 2018.

[15] J. Li, S. Zhang, Q. Wang et al., "Feasibility of using fly ash-slagbased binder for mine backfilling and its associated leaching risks," Journal of Hazardous Materials, vol. 400, article 123191, 2020. 
[16] J. Wu, Q. Yin, Y. Gao, B. Meng, and H. Jing, "Particle size distribution of aggregates effects on mesoscopic structural evolution of cemented waste rock backfill," Environmental Science and Pollution Research, vol. 28, no. 13, pp. 16589-16601, 2021.

[17] R. D. Lokhande, A. Prakash, K. B. Singh, and K. K. K. Singh, "Subsidence control measures in coalmines: a review," Journal of Scientific and Industrial Research, vol. 64, pp. 323-332, 2005.

[18] J. Roser, D. Potocnik, and M. Vulic, "Analysis of dynamic surface subsidence at the underground coal mining site in Velenje, Slovenia through modified sigmoidal function," Minerals, vol. 8, no. 2, p. 74, 2018.

[19] Z. Bian, X. Miao, S. Lei, S. E. Chen, W. Wang, and S. Struthers, "The challenges of reusing mining and mineral-processing wastes," Science, vol. 337, no. 6095, pp. 702-703, 2012.

[20] D. Ma, H. Duan, X. Li, Z. Li, Z. Zhou, and T. Li, "Effects of seepage-induced erosion on nonlinear hydraulic properties of broken red sandstones," Tunnelling and Underground Space Technology, vol. 91, article 102993, 2019.

[21] S. Raziperchikolaee, V. Alvarado, and S. Yin, "Microscale modeling of fluid flow-geomechanics-seismicity: relationship between permeability and seismic source response in deformed rock joints," Journal of Geophysical Research-Solid Earth, vol. 119, no. 9, pp. 6958-6975, 2014.

[22] M. Li, A. Li, J. Zhang, Y. Huang, and J. Li, "Effects of particle sizes on compressive deformation and particle breakage of gangue used for coal mine goaf backfill," Powder Technology, vol. 360, pp. 493-502, 2020.

[23] T. Minh and J. Birendra, "Coupling between transport and geomechanics affects spreading and mixing during viscous fingering in deformable aquifers," Advances in Water Resources, vol. 136, article 103485, 2020.

[24] J. Zhang, Y. Liu, N. Zhou, and M. Li, "Pore pressure evolution and mass loss of broken gangue during the seepage," Royal Society Open Science, vol. 5, no. 10, article 180307, 2018.

[25] Z. Huang, S. Li, K. Zhao, Y. Wu, W. Zeng, and H. Xu, "Estimating the hydraulic conductivity of deep fractured rock strata from high-pressure injection tests," Mine Water and The Environment, vol. 39, no. 1, pp. 112-120, 2020.

[26] W. Zeng, Z. Huang, Y. Wu, S. Li, R. Zhang, and K. Zhao, "Experimental investigation on mining-induced strain and failure characteristics of rock masses of mine floor," Geomatics Natural Hazards \& Risk, vol. 11, no. 1, pp. 491-509, 2020.

[27] L. Xiao, Q. Wu, C. Niu et al., "Application of a new evaluation method for floor water inrush risk from the Ordovician fissure confined aquifer in Xiayukou coal mine, Shanxi, China," Carbonates and Evaporites, vol. 35, no. 3, pp. 1-16, 2020.

[28] W. Perl, "A friction coefficient, series-parallel channel model for transcapillary flux of nonelectrolytes and water," Microvascular Research, vol. 6, no. 2, pp. 169-193, 1973.

[29] Y. B. Wang, D. W. Yin, S. J. Chen, L. Zhang, D. Liu, and Y. Sun, "Experimental study on properties of rock-cemented coal gangue-Fly ash backfill bimaterials with different coal gangue particle sizes," Advances in Civil Engineering, vol. 2020, 12 pages, 2020.
[30] J. Hou, Z. Guo, W. Liu, and Y. Zhang, "Mechanical properties and meso-structure response of cemented gangue-fly ash backfill with cracks under seepage- stress coupling," Construction and Building Materials, vol. 250, article 118863, 2020.

[31] C. Wang, B. Shen, J. Chen et al., "Compression characteristics of filling gangue and simulation of mining with gangue backfilling: an experimental investigation," Geomechanics and Engineering, vol. 20, no. 6, pp. 485-495, 2020.

[32] J. Y. Li and J. M. Wang, "Comprehensive utilization and environmental risks of coal gangue: a review," Journal of Cleaner Production, vol. 239, article 117946, 2019. 